\title{
Differences in Neural Activation for Object-Directed Grasping in Chimpanzees and Humans
}

\author{
Erin E. Hecht, ${ }^{1,2,3}$ Lauren E. Murphy, ${ }^{3,4,5}$ David A. Gutman, ${ }^{6,7}$ John R. Votaw, ${ }^{3,8}$ David M. Schuster, ${ }^{8}$ Todd M. Preuss, ${ }^{2,3}$ \\ Guy A. Orban, ${ }^{9}$ Dietrich Stout, ${ }^{1}$ and Lisa A. Parr ${ }^{2,3,7}$ \\ ${ }^{1}$ Department of Anthropology, ${ }^{5}$ Department of Psychology, ${ }^{6}$ Department of Biomedical Informatics, ${ }^{7}$ Department of Psychiatry and Behavioral Science, and \\ ${ }^{8}$ Department of Radiology and Imaging Sciences, School of Medicine, Emory University, Atlanta, Georgia 30322, ${ }^{2}$ Center for Translational Social \\ Neuroscience and ${ }^{3}$ Yerkes National Primate Research Center, Emory University, Atlanta, Georgia 30329, ${ }^{4}$ Department of Biology, Georgia State University, \\ Atlanta, Georgia 30302, and ${ }^{9}$ Department of Neuroscience, University of Parma, Italy
}

The human faculty for object-mediated action, including tool use and imitation, exceeds that of even our closest primate relatives and is a key foundation of human cognitive and cultural uniqueness. In humans and macaques, observing object-directed grasping actions activates a network of frontal, parietal, and occipitotemporal brain regions, but differences in human and macaque activation suggest that this system has been a focus of selection in the primate lineage. To study the evolution of this system, we performed functional neuroimaging in humans' closest living relatives, chimpanzees. We compare activations during performance of an object-directed manual grasping action, observation of the same action, and observation of a mimed version of the action that consisted of only movements without results. Performance and observation of the same action activated a distributed frontoparietal network similar to that reported in macaques and humans. Like humans and unlike macaques, these regions were also activated by observing movements without results. However, in a direct chimpanzee/human comparison, we also identified unique aspects of human neural responses to observed grasping. Chimpanzee activation showed a prefrontal bias, including significantly more activity in ventrolateral prefrontal cortex, whereas human activation was more evenly distributed across more posterior regions, including significantly more activation in ventral premotor cortex, inferior parietal cortex, and inferotemporal cortex. This indicates a more "bottom-up" representation of observed action in the human brain and suggests that the evolution of tool use, social learning, and cumulative culture may have involved modifications of frontoparietal interactions.

\section{Introduction}

Humans' manual interactions with objects are part of what sets us apart from the rest of the animal kingdom. We manipulate and alter objects individually and cooperatively; create and use tools; and understand, learn from, and copy each other's object-related actions in ways that other species do not. This faculty for objectmediated action creates a new medium for the elaboration of human culture and cognition and may provide a foundation for

Received May 22, 2013; revised July 12, 2013; accepted July 16, 2013.

Author contributions: E.E.H., J.R.V., D.M.S., G.A.O., D.S., and L.A.P. designed research; E.E.H., L.E.M., and D.S. performed research; T.M.P. contributed unpublished reagents/analytic tools; E.E.H., L.E.M., D.A.G., T.M.P., D.S., and L.A.P. analyzed data; E.E.H. wrote the paper.

This work was supported by the National Institutes of Health (Grant \#RR-00165 to the Yerkes National Primate Research Center superceded by Office of Research Infrastructure Programs/OD P510D11132; Grants \#MH58922 and \#F31MH086179-01 to E.E.H.; and Grants \#5P01 AG026423-03 and R01 MH068791 to L.A.P.), the Wenner-Gren Foundation (Dissertation Fieldwork Grant and Osmundsen Initiative Award 7699 Reference\#3681 to E.E.H.), and the Emory Center for Systems Imaging (Pilot Grants \#PET.HRRT.PS.001.12 and\#MRI.3T.PS.001.12 to D.S.). We thank the staffs of the Yerkes Imaging Center, Biomedical Imaging Technology Center, Wesley Woods Imaging Center, animal care facility, machine shop, and veterinary facility and James Rilling for sharing no-task chimpanzee control PET scans.

The authors declare no competing financial interests.

Correspondence should be addressed to Erin E. Hecht, Department of Anthropology, Emory University, 1557 Dickey Drive, 114 Anthropology Building, Atlanta, GA 30322. E-mail: ehecht@emory.edu.

DOI:10.1523/JNEUROSCI.2172-13.2013

Copyright $\odot 2013$ the authors $\quad 0270-6474 / 13 / 3314117-18 \$ 15.00 / 0$ key aspects of human uniqueness (Schiffer, 1999; Clark, 2008; Iriki and Sakura, 2008).

Human neuroimaging studies have identified a distributed frontoparieto-occipitotemporal network involved in the observation of object-directed grasping actions (Iacoboni et al., 1999; Buccino et al., 2001; Caspers et al., 2010; Jastorff et al., 2010; Molenberghs et al., 2012). Studies in macaques reveal a similar network, but with relatively greater frontal activation and less parietal activation during grasping observation ( $\mathrm{Ne}$ lissen et al., 2005) and relatively greater prefrontal activation when viewing objects (Denys et al., 2004). In particular, fMRI studies have found evidence of 3D-structure-from-motion processing in human but not macaque intraparietal sulcus (Vanduffel et al., 2002) and sensitivity to the observation of tool use in human but not macaque anterior inferior parietal cortex (Peeters et al., 2009). It has also been shown that macaque mirror neurons only respond to actions that have physical results on objects (transitive actions such as grasping an object) and not to actions that consist of movements without results (intransitive actions such as miming a grasping movement; Rizzolatti et al., 1996), whereas homologous human regions are activated by intransitive actions (Buccino et al., 2001; Binkofski and Buccino, 2006; Filimon et al., 2007; Lui et al., 2008). Therefore, evidence indicates that the human brain responds to observed object-related actions differently from 

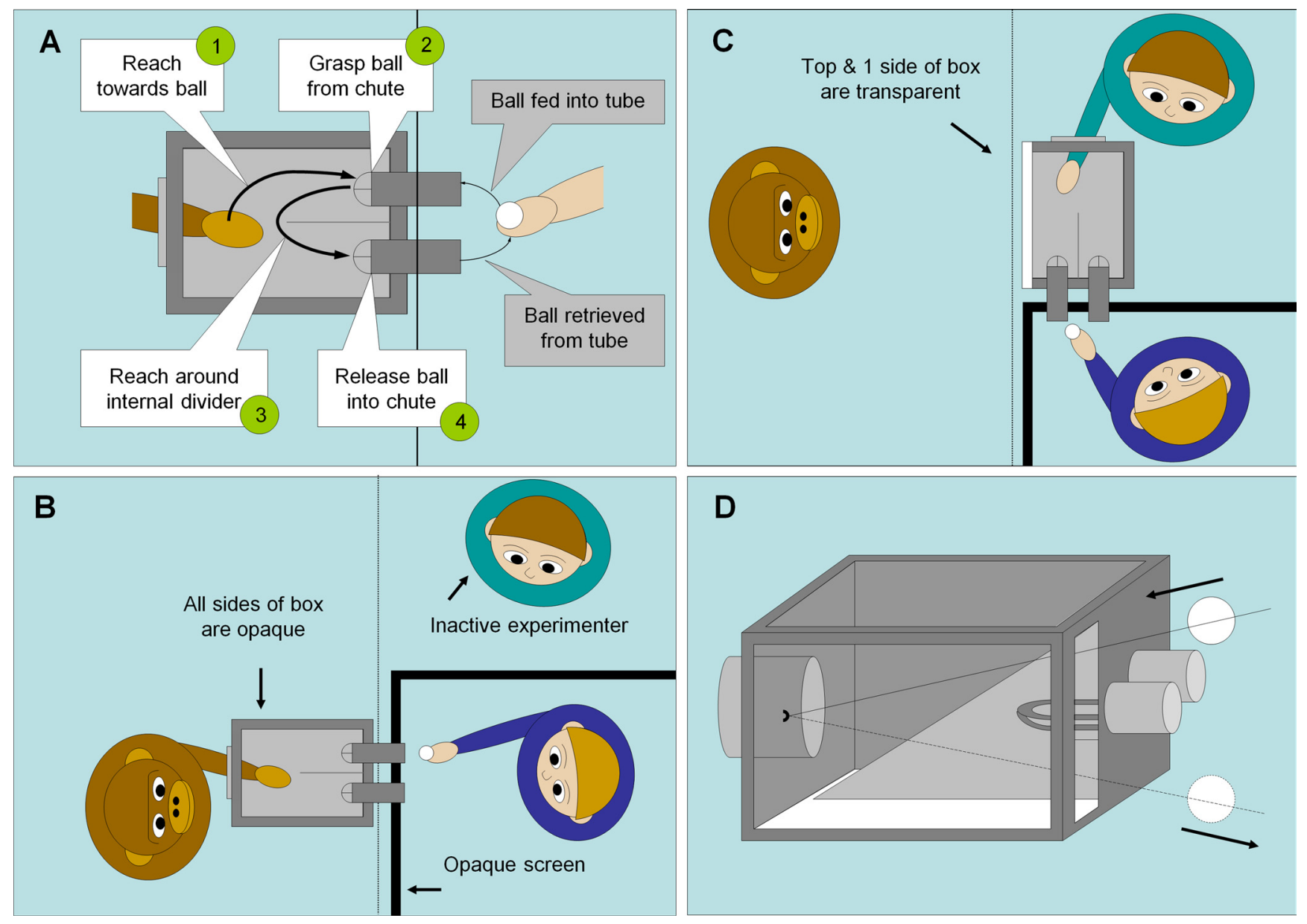

Figure 1. Chimpanzee behavioral tasks. $A$, Reach-to-grasp action used in tasks. The ball is fed into a downward-slanting chute. The chimpanzee reaches toward and grasps the ball, navigates around the internal divider, and places the ball into another chute, where it rolls back to the experimenter. $\boldsymbol{B}$, Action execution condition. The chimpanzee performed the reach-to-grasp action while an experimenter passed the ball through the chutes. This experimenter was hidden behind an opaque screen, but a second, inactive experimenter was visible. This controlled for the presence of a visible human in the observation condition and also allowed the chimpanzee's behavior to be monitored. All sides of the box were opaque, so the chimpanzee could not see his own hand movements. C, Transitive and intransitive observation conditions. The top and 1 side of the box were replaced with clear Plexiglas. The experimenter performing the actions was visible, but the second experimenter was hidden. In the transitive observation condition, the experimenter performed the actions as in $\boldsymbol{A}$. In the intransitive observation condition, the experimenter mimed these same actions without touching any object. $\boldsymbol{D}$, Control for the perception of object movement in the intransitive observation condition. The ball was slid in and out of the box along a transparent thread, interspersed with the experimenter's mimed grasping actions. The chimpanzee was unable to see the experimenter's hand moving the thread.

other primates, which has broad relevance for the evolution of human behavior.

To pinpoint any uniquely human features of these neural systems, it is crucial to perform direct comparisons with our closest living relatives, chimpanzees. Rhesus macaques, the most common neuroscience model species, are separated from humans by approximately 25 million years of divergent evolution (Goodman et al., 1998) and rarely or never produce many of the complex object-related behaviors that are characteristic of humans, such as tool use and imitation (Visalberghi and Fragazy, 2002). In contrast, chimpanzees do use tools (Goodall, 1964; Whiten et al., 1999), do imitate in some circumstances (Whiten et al., 2009), and are humans' closest living relatives, separated by approximately 6 million years (Goodman et al., 1998). Chimpanzee neuroscience research is extremely rare and difficult given that ethical and safety considerations preclude most of the neuroscience methods used in humans and monkeys. However, the Yerkes National Primate Research Center has developed the use of a functional neuroimaging method, FDG-PET, to map chimpanzee regional cerebral glucose metabolism during awake behavior (Rilling et al., 2007; Taglialatela et al., 2008; Parr et al., 2009;
Taglialatela et al., 2011). Building on these achievements, we performed a parallel PET imaging study in humans and chimpanzees. We characterize here the response properties of the chimpanzee grasping execution/observation network and also report a direct, quantitative chimpanzee/human comparison for grasping observation.

\section{Materials and Methods}

Subjects. Chimpanzee subjects included four individuals (two male, two female) housed at the Yerkes National Primate Research Center. All had previous experience working on cognitive behavioral tasks. Chimpanzee procedures were approved by the institutional animal care and use committee at Emory University. Human subjects included six individuals (three male, three female) recruited from the graduate and undergraduate student population at Emory University. All human subjects were neurologically and psychiatrically normal and were right-handed by selfreport. Human subjects gave written consent and procedures were approved by the institutional review board of Emory University.

Chimpanzee behavioral tasks. Chimpanzees underwent three functional neuroimaging conditions (Fig. 1): (1) performance of a manual, transitive (object-directed) grasping action; (2) observation of a human experimenter demonstrating the same action; and (3) observation of an 
intransitive version of this action in which the demonstrated grasping movement was mimed without touching any object. This intransitive condition also included the observation of object movement so that any differences in activation between the transitive and intransitive observation conditions could be attributed specifically to the presence or absence of an object-directed grasp. Chimpanzees performed grasping actions in the execution condition with the right hand; these actions were performed inside a metal box so that subjects were unable to view their own movements. The human demonstrator performed the actions in the observation conditions with the right hand in the same box. Chimpanzees were trained on the motor task for the execution condition using behavioral chaining. They were similarly trained to watch the demonstrated actions while sitting and not moving for the observation conditions. Subjects were considered fully trained when they could perform the intended behaviors (grasping or sitting still and watching) for $30 \mathrm{~min}$ with $<3$ min of off-target behavior. Therefore, by the time scans were acquired, subjects were very well practiced at the tasks. Subjects were offered small sips of sugar-free Kool-Aid when necessary to maintain motivation at the task. No subject received more than approximately 150 $\mathrm{ml}$ and the experimenter's hand motions when lifting the bottle were hidden. Scans from a previously published study were also available, in which chimpanzee subjects were freely resting in their enclosures without any specific motor task, perceptual stimulus, or behavioral instructions (Fig. 2 in Rilling et al., 2007). However, it is important to note that, in contrast to standard fMRI control tasks, which are highly controlled, this rest condition did include a low level of motor activity and the ability to observe normal environmental surroundings, because neither movement nor vision can be practically or ethically restrained in chimpanzees.

Human task. Human subjects underwent a transitive action observation condition analogous to the second chimpanzee condition. Human stimuli consisted of 12 separate videos, each $\sim 2 \mathrm{~s}$ in length, depicting object-directed, reach-to-grasp actions by a human hand (Peeters et al., 2009). The depicted actions included both precision and whole-hand grips of a ball and a block (both approximately golf ball sized) as well as a smaller pebble (approximately dime sized). Screenshots of these videos, as well as a photograph of the comparable chimpanzee stimulus, are shown in Figure 2. Videos were looped end-to-end in a quasirandom order with no repeats to produce a continuous 45 min stream. Human subjects were instructed to sit quietly without moving and observe the videos.

FDG dosage. FDG-PET uses FDG, a glucose analog radiolabeled with ${ }^{18} \mathrm{~F}$. FDG is taken up by cells in the same manner as glucose but becomes temporarily trapped inside the cell; photons that result from decay are detected by the scanner and metabolism then completes normally (Reivich et al., 1979). Chimpanzee subjects drank a $15 \mathrm{mCi}$ dose of FDG mixed in sugar-free Kool-Aid, performed the behavioral task for each condition, and then were anesthetized and scanned. Human subjects received a $10 \mathrm{mCi}$ intravenous dose of FDG, observed the perceptual stimuli, and then were scanned. The human dose was lower due to the direct, intravenous dosage method. Therefore, in scan images, brighter regions indicate areas of increased metabolism during the task. This method was developed at the Yerkes National Primate Research Center and is the only methodology available for functional neuroimaging in awake, behaving chimpanzees (Rilling et al., 2007; Taglialatela et al., 2008, 2011; Parr et al., 2009; ). FDG gray matter absorption after oral dosage rises slowly for approximately $10 \mathrm{~min}$ and then rises sharply (Parr et al., 2009). During initial chimpanzee behavioral training, it became apparent that it was difficult for our tasks to hold the chimpanzees' attention for sustained periods, and we wanted to ensure maximally focused behavior during the period of greatest FDG uptake. Therefore, in the $10 \mathrm{~min}$ after dosage, chimpanzees rested quietly in their cage. During this period, behavior was videotaped and monitored remotely via live feed to ensure that no actions took place that could confound image interpretation. Humans, other chimpanzees, and manipulatable objects were all removed from the subject's vicinity. Ten minutes after dosage, the behavioral task began.

Because each FDG-PET scan averages brain activity over the entire 45 min uptake period, the homogeneity of the subject's behavior during that period is crucial for linking brain activation to the task. Although the chimpanzees' behavior was not physically constrained, we were able to
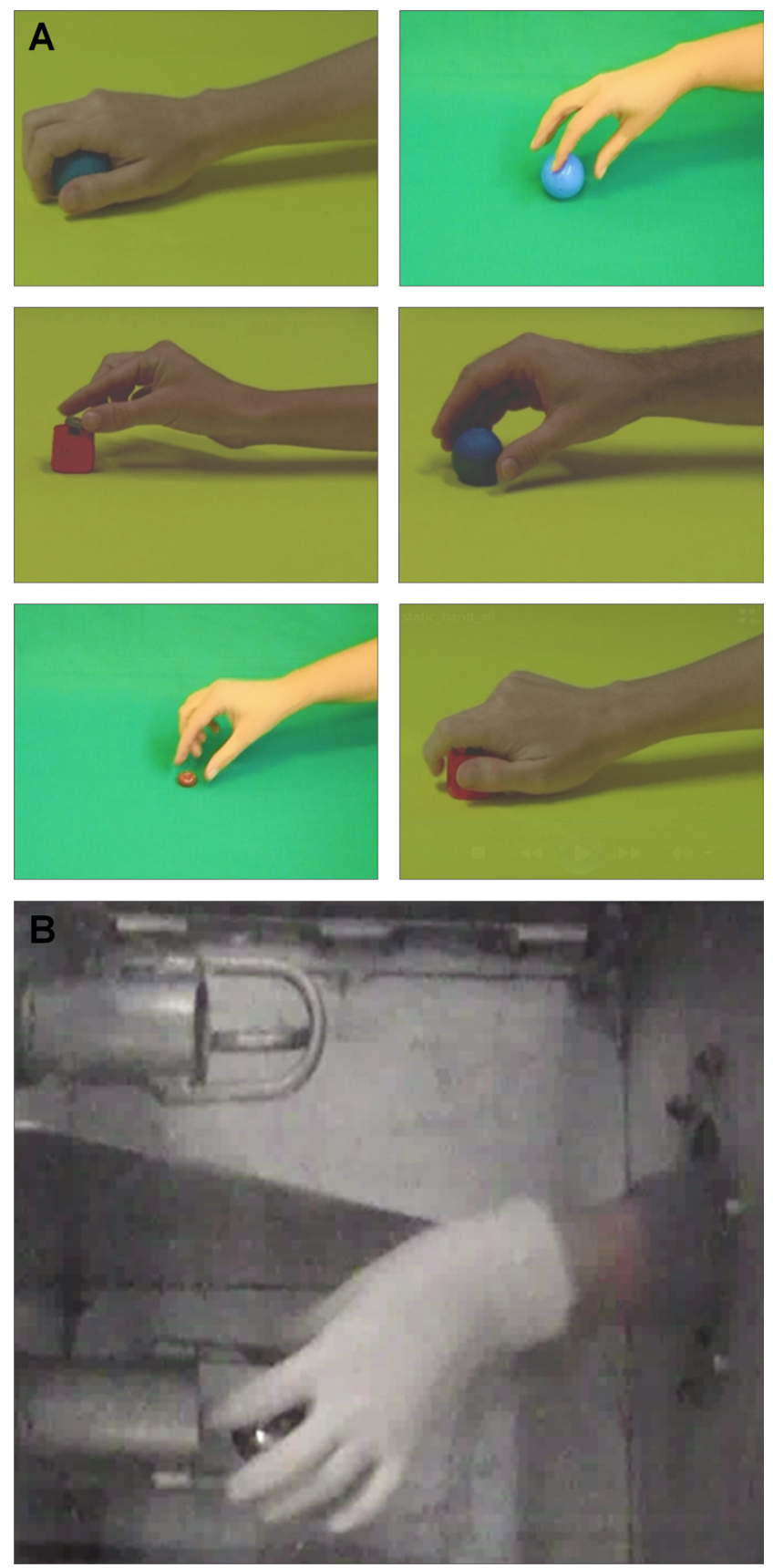

Figure 2. Transitive grasping stimuli observed by chimpanzees and humans. $\boldsymbol{A}$, Screenshots from human video stimuli (Peeters et al., 2009). $\boldsymbol{B}$, Photograph of chimpanzee live-action demonstration.

ensure behavioral homogeneity across conditions by only scanning subjects when their behavior conformed to predefined criteria. If the total time of non-task-related hand or mouth activity exceeded predefined thresholds, the scan was cancelled and reattempted at a later date. Between one and five chimpanzee scans were aborted for every one successfully obtained. The thresholds for cancellation were as follows: $>3 \mathrm{~min}$ performing mouth movements or reaching/grasping actions with the hand or arm; $>3 \mathrm{~min}$ in any other activity not involving the hands, arms, or mouth; $>10$ min being inactive but not engaged in the task. Behavior of both chimpanzee and human subjects between FDG dosage and scan acquisition is listed in Table 1. During the entire 45 min uptake period, chimpanzee subjects spent an average of 2:32 in non-task-related activity (5.62\% of total uptake time); humans spent an average of 2:22 (5.26\% of total uptake time). 
Table 1. Measurements and descriptions of non-task-related behavior for each chimpanzee and human subject during FDG uptake

\begin{tabular}{llll}
\hline Condition & Subject & Time & Description of non-task-related behavior \\
\hline Action execution & Chimp1 & $3: 08$ & Chew on ball, scratch/groom self, return ball through cage mesh, raspberry, aggression display \\
& Chimp 2 & $1: 59$ & Chew on ball, bite fingernails, scratch/groom self \\
& Chimp 3 & $1: 20$ & Swing, climb, move barrel, manipulate cage lock \\
Transitive observation & Chimp 4 & $5: 00$ & Food beg, spit water at experimenters \\
& Chimp1 & $1: 00$ & Groom self \\
& Chimp 2 & $2: 15$ & Swing, climb, manipulate own feet, bite fingernails, food beg, aggression display, throw feces \\
& & & at experimenters, scratch/groom self, pat own head, manipulate cage locks \\
& Chimp 3 & $1: 18$ & Scratch/groom self, aggression display \\
Intransitive observation & Chimp 4 & $1: 36$ & Suck thumb, poke finger through cage mesh, scratch/groom self \\
& Chimp1 & $3: 55$ & Scratch/groom self, spit water at experimenters \\
& Chimp 2 & $3: 34$ & Pick up hairs from floor, bite/lick cage mesh, scratch/groom self, climb \\
& Chimp 3 & $0: 37$ & Climb \\
Transitive observation & Chimp 4 & $4: 42$ & Spit water at experimenters, scratch/groom self, manipulate own feet, gurgle juice, food beg \\
& Human 1 & $0: 48$ & Manipulate wristwatch, scratch face, yawn, adjust shirt \\
& Human 2 & No video due to equipment error & \\
& Human 3 & $04: 46$ & Head nod, fall asleep \\
& Human 4 & $04: 29$ & Yawn, manipulate blanket \\
& Human 5 & $01: 38$ & Rearrange blanket, yawn \\
& Human 6 & $00: 07$ & Yawn, stretch, scratch face \\
\hline
\end{tabular}

Image acquisition. Human subjects were scanned 45 min after dosage. At this same time point, chimpanzee subjects were sedated with Telazol (4-5 mg/kg, i.m.), anesthetized with propofol $(10 \mathrm{mg} / \mathrm{kg} / \mathrm{h})$, and then scanned. Both human and chimpanzee subjects were scanned using previously described procedures (Rilling et al., 2007; Parret al., 2009) with the same Siemens high-resolution research tomograph, which acquires 207 slices ( $1.2 \mathrm{~mm}$ slice separation) with a reconstructed image resolution of $\sim 3 \mathrm{~mm}$. Images were reconstructed with corrections for motion, attenuation, scatter, randoms, and dead time. PET image pixel size was $1.22 \mathrm{~mm}$ isotropic. Chimpanzee T1-weighted MRI scans were acquired as described previously (Rilling et al., 2007; Parr et al., 2009) with a 3.0-Tesla Trio scanner (Siemens) at a resolution of $0.63 \times 0.63 \times 0.60$ $\mathrm{mm}$. Human T1-weighted MRI scans were also acquired with a 3.0-Tesla Trio scanner (Siemens) at a resolution of $1.0 \times 1.0 \times 1.0 \mathrm{~mm}$.

Image analysis. Chimpanzee and human images were analyzed in exactly the same way. PET images were coregistered to and masked with skull-stripped MRI images so that only voxels relating to the brain would be analyzed. Each image was normalized by dividing it by its own mean voxel value so that images could be compared across subjects and conditions. Each image was smoothed using a $4 \mathrm{~mm}$ kernel. In the chimpanzee dataset, group statistical analyses were performed using SPM to identify differences in activation between conditions. Scans were analyzed using a full factorial model in SPM5 with one factor (condition) with four levels (execution, transitive observation, intransitive observation, rest). For these group-level SPM analyses, the threshold was set at $p<0.05$, uncorrected. This liberal threshold was chosen due to the relative similarity between the experimental and control conditions (i.e., the no-task control scans included a low but non-zero level of motor actions and were not free from visual stimulation because the subjects could see their normal surroundings). In both the chimpanzee and human datasets, we also performed within-subjects analyses. In these individual analyses, each image was thresholded to include only the top $1 \%$ of the robust mean of the histogram of voxel values in that condition. This threshold was chosen in the interest of providing a relatively conservative map of the wider distributed network involved in the tasks (Rilling et al., 2007 used 5\%). The number of activated voxels in each ROI, in each condition, in each subject was calculated. 3D images of brain activations were created using MRIcron with an $8 \mathrm{~mm}$ search depth. PET activations were overlaid on our nonlinearly averaged, 36-subject chimpanzee brain template (Li et al., 2010) or the MNI $1 \mathrm{~mm}$ nonlinear human template for the group analyses and on each subject's own T1 MRI scan for the withinsubjects analyses.

ROI definition. A map of chimpanzee cortical anatomy drawn on our chimpanzee brain template is included so that readers can orient themselves to the location of our ROIs and surrounding brain regions (Fig. $3 A$ ). For the chimpanzee analyses, ROIs were drawn by hand in each subject's T1 MRI image (Fig. 3B). Human Brodmann area (BA) 44 is homologous to chimpanzee FCBm, which occupies the pars opercularis of the inferior frontal gyrus (Bailey et al., 1950). Human BA 40 is homologous to chimpanzee areas $\mathrm{PFD} / \mathrm{PF}$, which occupy the anterior part of the supramarginal gyrus in inferior parietal cortex (Bailey et al., 1950). For the comparative chimpanzee/ human analyses, we used a larger set of ROIs covering most of frontal, parietal, and occipitotemporal cortex. These ROIs were drawn on the chimpanzee and human templates and were defined by an experienced comparative chimpanzee/human neuroanatomist (T.M.P.) on the basis of clearly identifiable landmarks and homologies in cytoarchitectonics, as described by previously published atlases and studies (Brodmannn, 1909; Economo and Parker, 1929; Bailey, 1948; Von Bonin, 1948; Bailey et al., 1950; Schenker et al., 2010). These ROIs are illustrated in Figure $11 A$ and are anatomically defined in Table 2.

\section{Results}

Characterization of chimpanzee grasping networks: action execution, transitive observation, and intransitive observation

Whole-brain group-level analyses using SPM

Initial whole-brain group-level comparisons revealed that the major differences between the experimental conditions and rest occurred in cerebellum and brainstem. Therefore, for further group-level statistical analyses, we masked the cerebellum and brainstem to investigate more directly activation differences in the cerebrum.

SPM comparisons between conditions are rendered on the $3 \mathrm{D}$ chimpanzee template brain in Figure 4; coronal slices are shown in Figure 5; coordinates for activation peaks are given in Table 3. The Execution $>$ Rest contrast revealed left-lateralized clusters of activation in primary motor cortex (in the vicinity of the hand and arm representations), ventral premotor cortex, inferior frontal gyrus, inferior parietal cortex, and lateral temporal cortex (Fig. 4A, 3D renderings; Fig. 5A, coronal slices). Similar frontal and temporal regions were active in the Transitive Observation $>$ Rest and Intransitive Observation $>$ Rest contrasts (Fig. $4 B, C$, 3D renderings; Fig. $5 B, C$, coronal slices).

The SPM contrasts for Execution > Transitive Observation and Execution $>$ Intransitive Observation produced clusters in inferior parietal cortex (Fig. $4 D, E, 3 \mathrm{D}$ renderings; Fig. $5 D, E$, coronal slices). The anterior aspect of this cluster is 
A
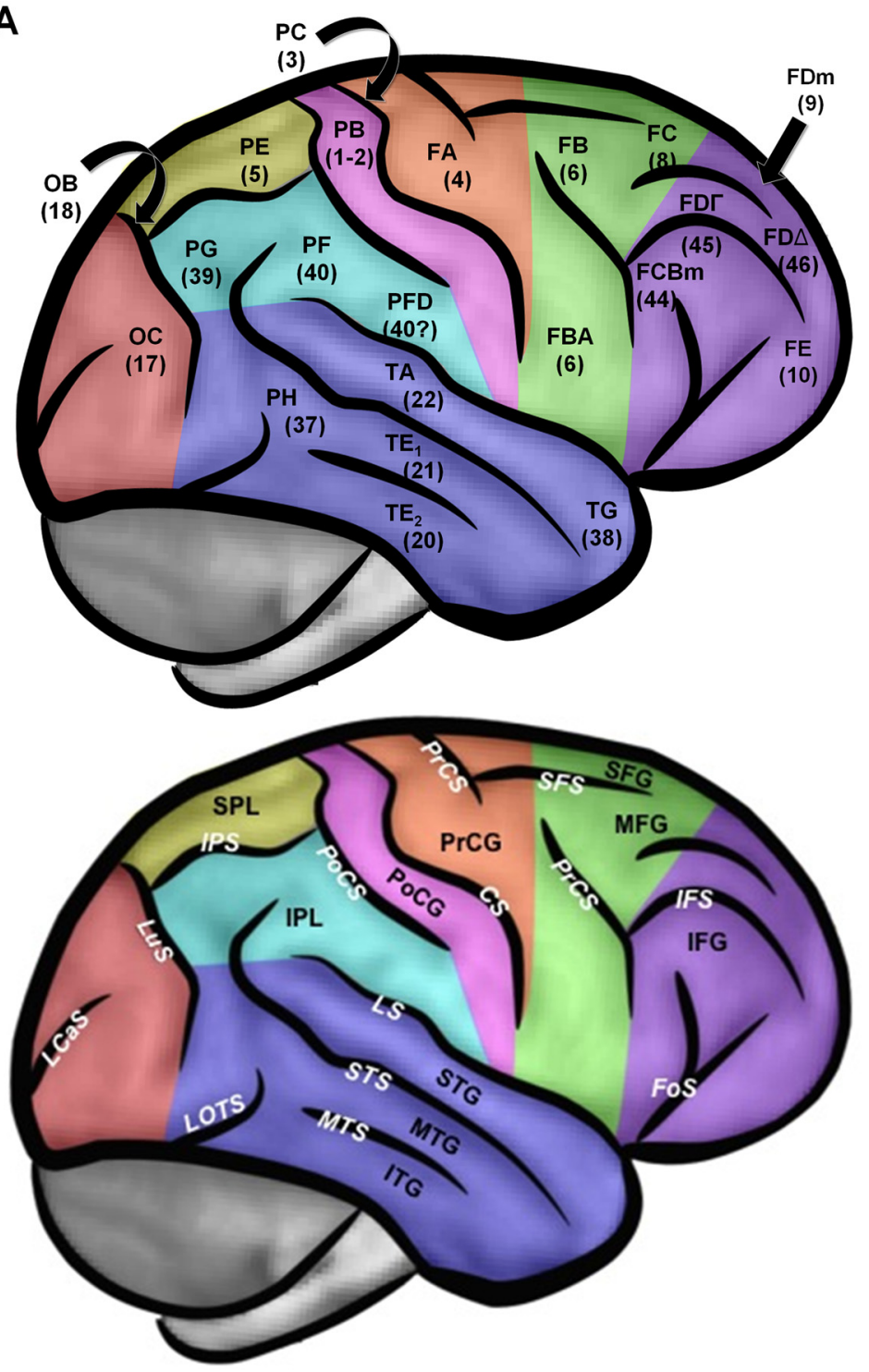

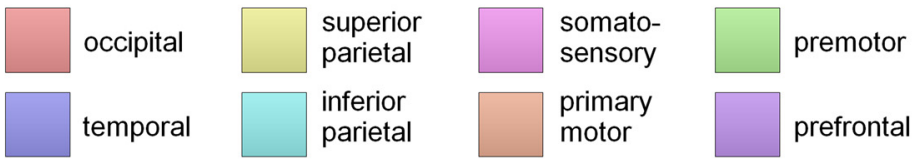

\section{B}

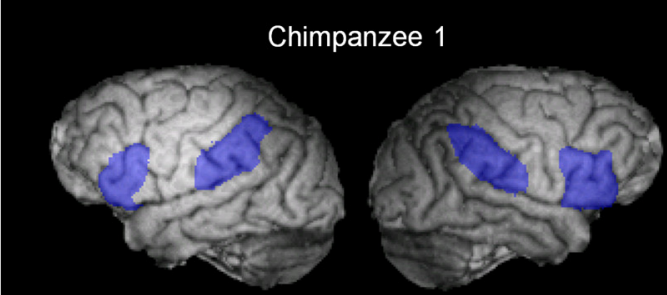

Chimpanzee 2

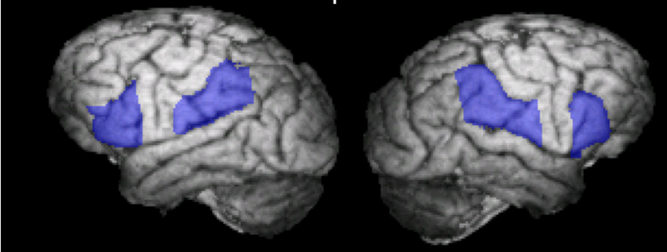

Chimpanzee 3

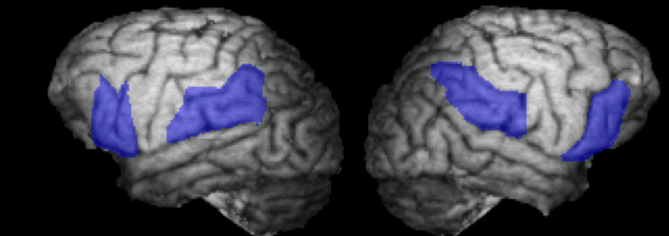

Chimpanzee 4

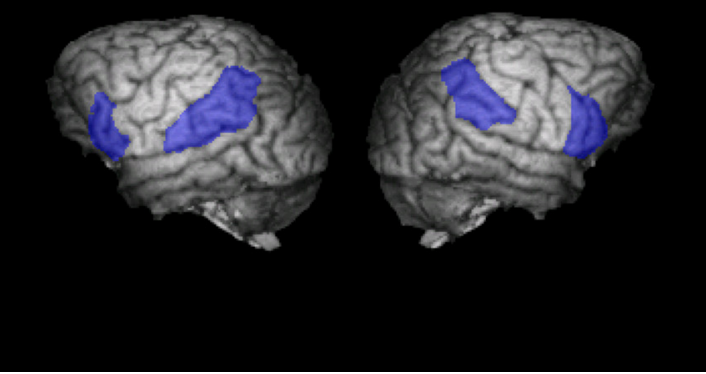

Figure 3. Chimpanzee cortical anatomy and ROls. Left hemispheres appear on the left. A, Chimpanzee cortical anatomy. Architectonic areas (top) and surface morphology of cerebral cortex (bottom). The nomenclature for sulci and gyri is based on Bailey et al. (1950), although our abbreviations follow more modern conventions. Cortical areas are denoted according to the system of Bailey et al. (1950) and Bailey (1948) based on Economo's system in humans (Economo and Parker, 1929). For most areas, there is a fairly straightforward correspondence between the Bailey et al. (1950) areas and their counterparts in Brodmannn's human map (Brodmannn, 1909; Von Bonin, 1948), and we have added Brodmannn numbers in parentheses below the Bailey et al. (1950) symbols. Areas thought to be homologous to BA 44 and BA 45 of humans occupy the posterior inferior frontal gyrus and adjacent part of the inferior frontal sulcus in chimpanzees, as discussed by Schenker et al. (2010). B, ROIs in FCBm and PFD/PF in each subject. CS, central sulcus; FOS, frontoorbital sulcus; IFG, inferior frontal gyrus; IFS, inferior frontal sulcus; IPL, inferior parietal lobule; IPS, intraparietal sulcus; LCaS, lateral calcarine sulcus; LOTS, lateral occipitotemporal sulcus; LS, lateral sulcus; LuS, lunate sulcus; MFG, middle frontal gyrus; MTG, middle temporal gyrus; MTS, middle temporal sulcus; PoCG, postcentral gyrus; PoCS, postcentral sulcus; PrCG, precentral gyrus; PrCS, precentral sulcus; SFG, superior frontal gyrus; SFS, superior frontal sulcus; SPL, superior parietal lobule.

most likely in area AIP. Small clusters also occurred around the border of the precentral gyrus (area FBA, homologous to BA 6) and pars opercularis of the inferior frontal gyrus (area FCBm, homologous to BA 44).

The SPM contrasts for Transitive Observation $>$ Execution and Intransitive Observation $>$ Execution produced clusters in lateral temporal cortex, especially on the right side (Fig. 4F, G, 3D renderings; Fig. 5F, G, coronal slices). These contrasts also produced clusters in anterior inferior frontal gyrus, probably area FCBm (homologous to BA 44), as well as scattered small clusters in dorsal premotor and dorsolateral prefrontal cortex, probably including the frontal eye fields (area FDГ).

The SPM contrast for Transitive Observation $>$ Intransitive Observation produced clusters at the border between the 
Table 2. Anatomical definitions of homologous human and chimpanzee ROIs

\begin{tabular}{|c|c|c|c|c|}
\hline \multirow[b]{2}{*}{$\underline{\mathrm{R}} \mathrm{Ol}$} & \multicolumn{2}{|l|}{ Chimpanzees } & \multicolumn{2}{|l|}{ Humans } \\
\hline & Anatomical description & Cyto-architectonic region(s) & Anatomical description & Cyto-architectonic region(s) \\
\hline Lateral occipital cortex (LOC) & $\begin{array}{l}\text { Its anterior border is a line drawn straight up } \\
\text { from the occipital notch following the } \\
\text { inferior extension of the STS. Its posterior } \\
\text { border includes both the banks and the } \\
\text { fundus of the lunate sulcus. It includes both } \\
\text { banks of the medial parietooccipital fissure. }\end{array}$ & OA (BA 19) & $\begin{array}{l}\text { Same, except its posterior border is a } \\
\text { curved line placed half way to the } \\
\text { pole. }\end{array}$ & BA 19 \\
\hline Inferotemporal cortex (IT) & $\begin{array}{l}\text { Lateral temporal cortex inferior to the superior } \\
\text { central sulcus extending ventrally to the } \\
\text { border with the hippocampal formation. Its } \\
\text { anterior border is the temporal pole and its } \\
\text { posterior border is an imaginary vertical } \\
\text { line drawn up from the occipital notch. }\end{array}$ & $\begin{array}{l}\text { TE1 (BA 21), TE2 (BA 20), } \\
\text { PH (BA 37) }\end{array}$ & Same. & BA 21, BA 20, BA 37 \\
\hline Superior temporal sulcus (STS) & $\begin{array}{l}\text { Includes both banks and fundus. Its posterior } \\
\text { border is the imaginary extension of the } \\
\text { inferior terminus of the STS parallel to but } \\
\text { anterior to the lunate sulcus. }\end{array}$ & & $\begin{array}{l}\text { Same, except its posterior termina- } \\
\text { tion is vertical line from occipital } \\
\text { notch. }\end{array}$ & \\
\hline Inferior parietal cortex (IPL) & $\begin{array}{l}\text { Its anterior border is the posterior bank of } \\
\text { postcentral sulcus. Its posterior border is a } \\
\text { vertical line drawn up from the termination } \\
\text { of the inferior sulcus that extends off the } \\
\text { posterior end of the STS. }\end{array}$ & PFD, PF (BA 40/7b), PG (BA 39/7a) & $\begin{array}{l}\text { Its anterior border is the fundus of } \\
\text { the postcentral sulcus. Its poste- } \\
\text { rior border is vertical line drawn } \\
\text { up from the occipital notch. }\end{array}$ & BA 40, BA 39 \\
\hline Superior parietal cortex (SPL) & $\begin{array}{l}\text { Its anterior border is the posterior bank of } \\
\text { postcentral sulcus. Its posterior border is a } \\
\text { vertical line drawn up from the termination } \\
\text { of the inferior sulcus that extends off the } \\
\text { posterior end of the STS. }\end{array}$ & PEm (BA 5), PEp (BA 5) & $\begin{array}{l}\text { Its anterior border is the fundus of } \\
\text { the postcentral sulcus. Its poste- } \\
\text { rior border is a vertical line drawn } \\
\text { up from the occipital notch. }\end{array}$ & BA 5, BA 7 \\
\hline $\begin{array}{l}\text { Primary and secondary somatosensory } \\
\text { cortex (S1-S2) }\end{array}$ & $\begin{array}{l}\text { Its anterior border is the fundus of the central } \\
\text { sulcus. Its posterior border is the fundus of } \\
\text { postcentral sulcus. }\end{array}$ & $\mathrm{PB}(\mathrm{BA} 3, \mathrm{BA}$ 1), $\mathrm{PC}(\mathrm{BA} 2)$ & Same. & $\mathrm{BA} 3, \mathrm{BA} 1, \mathrm{BA} 2$ \\
\hline Primary motor cortex (M1) & $\begin{array}{l}\text { Its posterior border is the fundus of the central } \\
\text { sulcus. Its anterior border is an imaginary } \\
\text { line drawn straight up from the intersec- } \\
\text { tion of the inferior frontal sulcus and the } \\
\text { central sulcus. At its inferior aspect, the ROI } \\
\text { exists entirely inside the central sulcus. At } \\
\text { its superior aspect, the ROl extends past the } \\
\text { dorsal precentral sulcus. }\end{array}$ & $\mathrm{FA}(\mathrm{BA} 4)$ & $\begin{array}{l}\text { Its posterior border is the fundus of } \\
\text { the central sulcus. Its anterior } \\
\text { border is a vertical line from the } \\
\text { lateral sulcus to the superior tip of } \\
\text { superior precentral sulcus. }\end{array}$ & BA 4 \\
\hline Dorsal premotor cortex (PMd) & $\begin{array}{l}\text { At its dorsal aspect, it extends anteriorly to an } \\
\text { imaginary line drawn from the tip of the } \\
\text { inferior precentral sulcus at a } 90 \text { degree } \\
\text { angle with the lateral sulcus. The inferior } \\
\text { part of the ROl is bordered anteriorly at the } \\
\text { inferior frontal sulcus, curving down and } \\
\text { back to meet the PMv ROI. The border } \\
\text { between PMd and PMv is an imaginary line } \\
\text { drawn parallel to the lateral sulcus at the } \\
\text { dorsal tip of the frontooccipital sulcus so } \\
\text { that the superior borders of PMv and } \\
\text { Broca's area are continuous. }\end{array}$ & $\mathrm{FB}(\mathrm{BA} 6), \mathrm{FC}(\mathrm{BA} 8)$ & $\begin{array}{l}\text { Its posterior border is a vertical line } \\
\text { from the lateral sulcus to the } \\
\text { superior tip of the superior pre- } \\
\text { central sulcus. Its anterior border } \\
\text { is a } 45 \text { degree line from the an- } \\
\text { terosuperior edge of the PMv ROI. } \\
\text { The border between PMd and } \\
\text { PMv is the gyrus that splits the } \\
\text { superior and inferior precentral } \\
\text { sulci. }\end{array}$ & BA $6, \mathrm{BA} 8$ \\
\hline Ventral premotor cortex (PMv) & $\begin{array}{l}\text { Bordered posteriorly by the M1/S1 ROI, superi- } \\
\text { orly as described above, and anteriorly by } \\
\text { the inferior precentral sulcus. }\end{array}$ & FBA (BA 6) & $\begin{array}{l}\text { Its anterior border is the inferior } \\
\text { precentral sulcus. Its posterior } \\
\text { border is a vertical line from the } \\
\text { lateral sulcus to the superior tip of } \\
\text { superior precentral sulcus (M1). } \\
\text { Its superior border is the gyrus } \\
\text { that splits the inferior and supe- } \\
\text { rior precentral gyri. }\end{array}$ & BA 6 \\
\hline
\end{tabular}




\section{Table 2. Continued}

\begin{tabular}{|c|c|c|c|c|}
\hline \multirow[b]{2}{*}{ ROI } & \multicolumn{2}{|l|}{ Chimpanzees } & \multicolumn{2}{|l|}{ Humans } \\
\hline & Anatomical description & Cyto-architectonic region(s) & Anatomical description & Cyto-architectonic region(s) \\
\hline 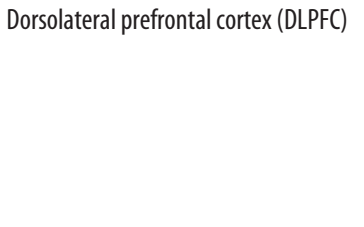 & $\begin{array}{l}\text { Bordered dorsally by the interhemispheric } \\
\text { fissure, posteriorly by the PMd ROI, inferi- } \\
\text { orly by the Broca's area ROI, and anteriorly } \\
\text { by an imaginary line that is an extension of } \\
\text { the orbital sulcus drawn past the tip of the } \\
\text { middle frontal sulcus. }\end{array}$ & $\mathrm{FDm}(\mathrm{BA} 9), \mathrm{FD} \delta(\mathrm{BA} 46)$ & $\begin{array}{l}\text { Its inferior border is the inferior } \\
\text { frontal sulcus. Its anterior border } \\
\text { is a } 45 \text { degree line drawn from tip } \\
\text { of anterior horizontal ramus (the } \\
\text { sulcus that borders the anterior } \\
\text { edge of Broca's area). }\end{array}$ & BA 9, BA 46 \\
\hline Ventrolateral prefrontal cortex (VLPFC) & $\begin{array}{l}\text { Includes the pars opercularis and pars triangu- } \\
\text { laris of the inferior frontal gyrus. Bordered } \\
\text { posteriorly by the inferior precentral sulcus, } \\
\text { anteriorly by the small sulcus that extends } \\
\text { anteriorly from the frontoorbital sulcus, } \\
\text { and superiorly by the inferior frontal sulcus. }\end{array}$ & FCBm (BA 44), FDp (BA 45) & Same. & BA 44, BA 45 \\
\hline
\end{tabular}

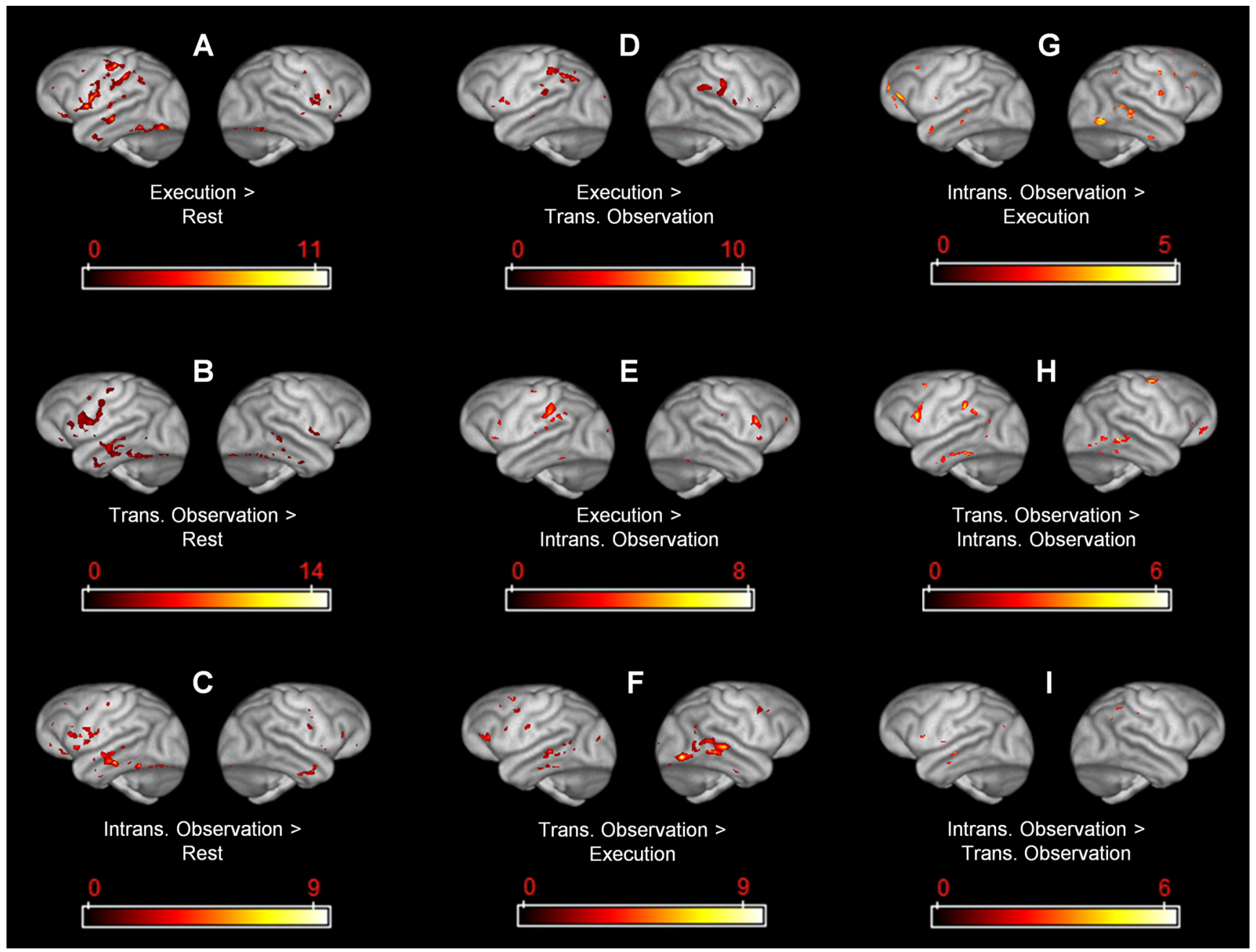

Figure 4. 3D surface renderings of group-level SPM statistical comparisons between conditions. Left hemispheres appear on the left. SPM5 analysis thresholded at $p<0.05 . A$, Execution $>$ Rest. $\boldsymbol{B}$, Transitive Observation $>$ Rest. C, Intransitive 0bservation $>$ Rest. $\boldsymbol{D}$, Execution $>$ Transitive Observation. $\boldsymbol{E}$, Execution $>$ Intransitive 0bservation. $\boldsymbol{F}$, Transitive 0bservation $>$ Execution. $\boldsymbol{G}$, Intransitive Observation $>$ Execution. $\boldsymbol{H}$, Transitive Observation $>$ Intransitive Observation. I, Intransitive Observation > Transitive Observation.

left precentral and inferior frontal gyri, left inferior parietal cortex, left dorsal premotor cortex, right dorsal premotor or primary motor cortex, right orbitofrontal cortex, and bilateral lateral temporal cortex (Fig. 4H, 3D renderings; Fig. 5H, coronal slices). Again, the anterior inferior parietal activations are most likely in area AIP. The opposite contrast, Intransitive
Observation $>$ Transitive Observation, produced small clusters at the border of the left precentral and inferior frontal gyri (located more ventrally than the Transitive $>$ Intransitive cluster), left anterior superior temporal sulcus and middle temporal gyrus, and right inferior parietal cortex (Fig. 4I, 3D renderings; Fig. 5I, coronal slices). 


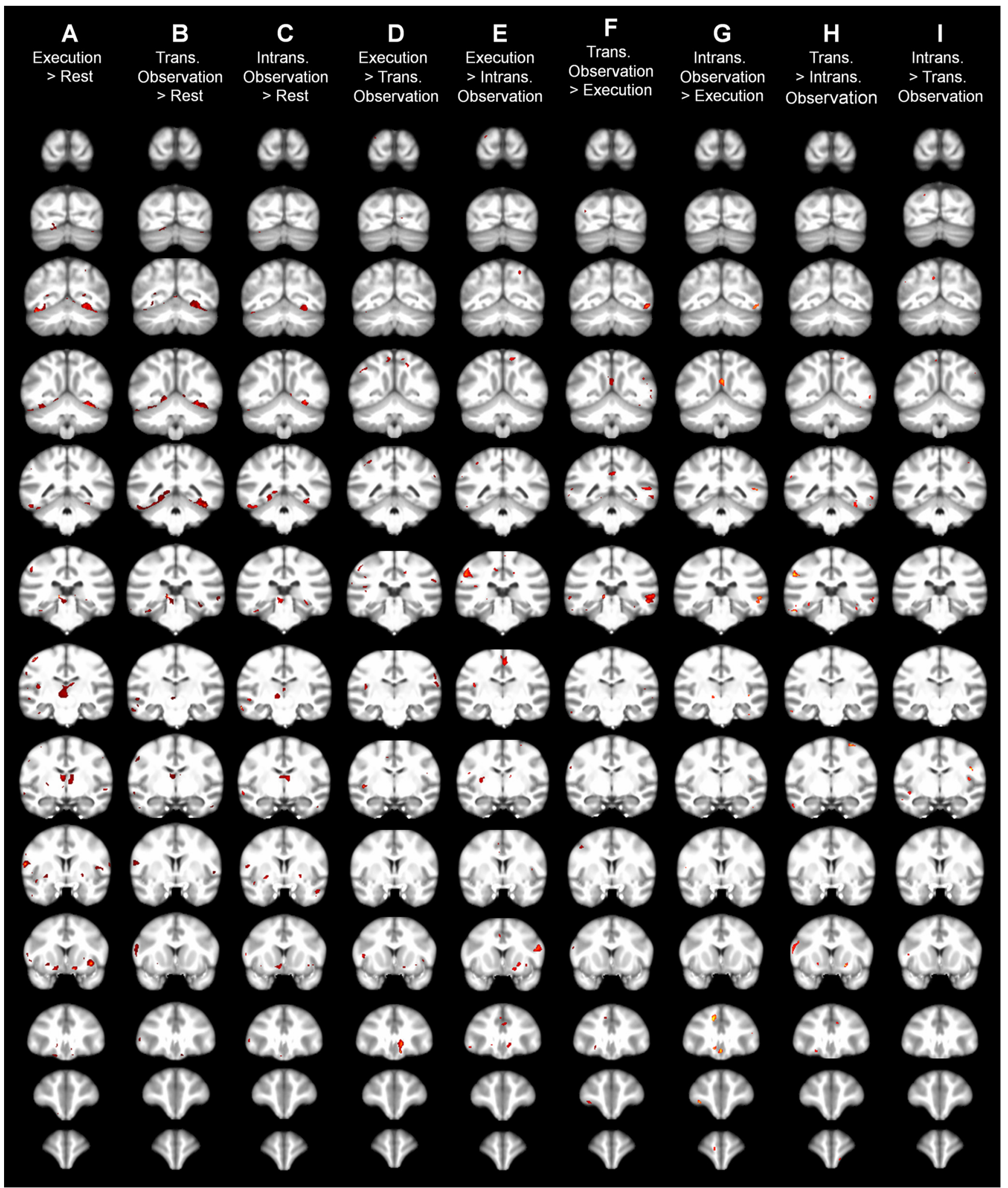

Figure 5. Coronal slices of group-level SPM statistical comparisons between conditions. Left hemispheres appear on the left. SPM5 analysis thresholded at $p<0.05$.

Whole-brain individual subject-level analyses using a $1 \%$ threshold

Figure 6 shows the top $1 \%$ of activity in each subject's scan in each condition. All action conditions activated similar frontoparietal regions, including central sulcus, precentral and postcentral gyri, dorsal and ventral premotor cortex, ventrolateral prefrontal cor- tex, dorsolateral prefrontal cortex (probably including the frontal eye fields), and inferior and superior parietal cortex. Individual subjects' activations are overlaid in a group composite map (Fig. $7 A-C, 3 \mathrm{D}$ renderings; Fig. $8 A-C$, coronal slices), which shows the number of subjects with above-threshold activation at a given voxel in each condition. The transitive and intransitive observa- 
Table 3. Cluster sizes; $T, Z$, and $p$ values; and coordinates of activation peak(s) for each cluster from the nine SPM analyses shown in Figures 4 and 5

\begin{tabular}{|c|c|c|c|c|}
\hline Cluster size & $T$ & $Z$ & $p$ & $x, y, z(\mathrm{~mm})$ of peak $(\mathrm{s})$ \\
\hline \multicolumn{5}{|c|}{ Execution $>$ Rest } \\
\hline \multirow[t]{3}{*}{1851} & 7.65 & 3.65 & 0 & $-7,-24,1$ \\
\hline & 5.13 & 3.07 & 0.001 & $4,-4,5$ \\
\hline & 3.85 & 2.64 & 0.004 & $0,-18,2$ \\
\hline \multirow[t]{3}{*}{1222} & 6.39 & 3.39 & 0 & $-28,-49,-12$ \\
\hline & 6.09 & 3.32 & 0 & $-33,-33,-12$ \\
\hline & 5.11 & 3.06 & 0.001 & $-20,-44,-11$ \\
\hline \multirow[t]{3}{*}{1130} & 9.47 & 3.95 & 0 & $22,-41,-12$ \\
\hline & 5.36 & 3.13 & 0.001 & $15,-45,-9$ \\
\hline & 3.66 & 2.56 & 0.005 & $25,-48,-14$ \\
\hline \multirow[t]{3}{*}{897} & 8.04 & 3.72 & 0 & $-37,2,10$ \\
\hline & 8.03 & 3.72 & 0 & $-30,5,4$ \\
\hline & 2.59 & 2.05 & 0.02 & $-36,0,19$ \\
\hline \multirow[t]{2}{*}{465} & 10.73 & 4.11 & 0 & $24,10,2$ \\
\hline & 2.38 & 1.93 & 0.027 & $22,2,-3$ \\
\hline \multirow[t]{2}{*}{337} & 7.65 & 3.65 & 0 & $6,10,-6$ \\
\hline & 2.89 & 2.2 & 0.014 & $14,3,-1$ \\
\hline \multirow[t]{2}{*}{306} & 4.34 & 2.82 & 0.002 & $-10,10,-6$ \\
\hline & 3.54 & 2.51 & 0.006 & $-6,22,-2$ \\
\hline \multirow[t]{2}{*}{289} & 11.53 & 4.21 & 0 & $-29,-16,32$ \\
\hline & 2.28 & 1.87 & 0.031 & $-24,-10,35$ \\
\hline \multirow[t]{2}{*}{271} & 6.26 & 3.36 & 0 & $-33,-22,24$ \\
\hline & 2.26 & 1.86 & 0.032 & $-33,-14,17$ \\
\hline 247 & 6.78 & 3.48 & 0 & $-37,-14,-6$ \\
\hline 247 & 2.47 & 1.98 & 0.024 & $-18,12,0$ \\
\hline 197 & 3.21 & 2.36 & 0.009 & $32,3,6$ \\
\hline 124 & 2.92 & 2.22 & 0.013 & $-19,2,-2$ \\
\hline 105 & 3.52 & 2.5 & 0.006 & $5,15,2$ \\
\hline 100 & 2.59 & 2.05 & 0.02 & $-8,15,7$ \\
\hline 84 & 3.57 & 2.52 & 0.006 & $-25,-16,8$ \\
\hline 74 & 2.51 & 2 & 0.023 & $-30,0,-19$ \\
\hline 66 & 3.01 & 2.27 & 0.012 & $37,3,10$ \\
\hline 66 & 2.86 & 2.19 & 0.014 & $-24,-10,26$ \\
\hline 65 & 2.7 & 2.1 & 0.018 & $-11,-44,-7$ \\
\hline 62 & 3.63 & 2.54 & 0.005 & $-29,-34,23$ \\
\hline 59 & 2.64 & 2.07 & 0.019 & $15,-47,3$ \\
\hline 56 & 2.99 & 2.26 & 0.012 & $-10,-54,-10$ \\
\hline 55 & 2.72 & 2.11 & 0.017 & $-18,-47,2$ \\
\hline 54 & 5.08 & 3.05 & 0.001 & $-34,-14,6$ \\
\hline 46 & 8.11 & 3.73 & 0 & $18,-25,-3$ \\
\hline 38 & 3.52 & 2.5 & 0.006 & $35,-9,-2$ \\
\hline 38 & 2.72 & 2.12 & 0.017 & $-3,-35,-1$ \\
\hline 30 & 3.41 & 2.45 & 0.007 & $-24,-30,28$ \\
\hline 30 & 2.52 & 2.01 & 0.022 & $-15,-5,1$ \\
\hline 29 & 3.12 & 2.32 & 0.01 & $6,-41,-2$ \\
\hline 23 & 2.87 & 2.2 & 0.014 & $-25,13,1$ \\
\hline 23 & 2.3 & 1.88 & 0.03 & $-26,-2,1$ \\
\hline 22 & 2.65 & 2.08 & 0.019 & $34,10,13$ \\
\hline 21 & 2.97 & 2.25 & 0.012 & $-26,1,-6$ \\
\hline 21 & 2.15 & 1.79 & 0.037 & $12,-53,-7$ \\
\hline 15 & 2.03 & 1.71 & 0.043 & $4,19,-4$ \\
\hline 11 & 3.17 & 2.34 & 0.01 & $25,-33,-14$ \\
\hline 11 & 2.72 & 2.12 & 0.017 & $-38,-22,10$ \\
\hline \multicolumn{5}{|c|}{ Transitive Observation $>$ Rest } \\
\hline \multirow[t]{3}{*}{2398} & 14.83 & 4.53 & 0 & $21,-35,-7$ \\
\hline & 8.4 & 3.78 & 0 & $22,-41,-13$ \\
\hline & 7.87 & 3.69 & 0 & $19,-26,-6$ \\
\hline \multirow[t]{3}{*}{1560} & 8.56 & 3.81 & 0 & $-7,-24,1$ \\
\hline & 5.27 & 3.11 & 0.001 & $-9,-39,-4$ \\
\hline & 5.25 & 3.1 & 0.001 & $-23,-24,-13$ \\
\hline \multirow[t]{3}{*}{830} & 5.94 & 3.29 & 0.001 & $-34,2,10$ \\
\hline & 3.83 & 2.62 & 0.004 & $-34,9,14$ \\
\hline & 3.79 & 2.61 & 0.005 & $\begin{array}{l}-37,-5,16 \\
\quad \text { (Table continues.) }\end{array}$ \\
\hline
\end{tabular}

Table 3. Continued

\begin{tabular}{|c|c|c|c|c|}
\hline Cluster size & $T$ & $Z$ & $p$ & $x, y, z(\mathrm{~mm})$ of peak(s) \\
\hline \multirow[t]{2}{*}{546} & 3.11 & 2.31 & 0.01 & $-15,3,1$ \\
\hline & 2.6 & 2.05 & 0.02 & $-18,12,2$ \\
\hline \multirow[t]{2}{*}{455} & 5.5 & 3.17 & 0.001 & $-35,-14,-6$ \\
\hline & 3.31 & 2.41 & 0.008 & $-36,-16,-14$ \\
\hline \multirow[t]{3}{*}{267} & 3.55 & 2.51 & 0.006 & $-22,-49,-6$ \\
\hline & 3.17 & 2.34 & 0.01 & $-21,-43,-12$ \\
\hline & 2.41 & 1.95 & 0.026 & $-28,-49,-14$ \\
\hline 239 & 3.21 & 2.36 & 0.009 & $-3,-9,10$ \\
\hline 133 & 3.05 & 2.28 & 0.011 & $-29,-5,-21$ \\
\hline 108 & 4.52 & 2.88 & 0.002 & $-12,-59,-14$ \\
\hline 98 & 2.79 & 2.15 & 0.016 & $-7,15,8$ \\
\hline 94 & 3.42 & 2.45 & 0.007 & $34,-1,3$ \\
\hline 70 & 3.59 & 2.53 & 0.006 & $37,-26,-1$ \\
\hline 63 & 2.34 & 1.9 & 0.028 & $4,-6,6$ \\
\hline 60 & 2.56 & 2.03 & 0.021 & $25,-10,-18$ \\
\hline 56 & 2.95 & 2.23 & 0.013 & $11,-53,-6$ \\
\hline 55 & 2.74 & 2.12 & 0.017 & $-26,-14,34$ \\
\hline 52 & 4.36 & 2.82 & 0.002 & $-33,-18,-7$ \\
\hline 45 & 3.39 & 2.44 & 0.007 & $22,-57,-14$ \\
\hline 45 & 3.26 & 2.38 & 0.009 & $-32,15,10$ \\
\hline 38 & 3.56 & 2.51 & 0.006 & $13,-30,-7$ \\
\hline 38 & 3.13 & 2.32 & 0.01 & $-27,3,5$ \\
\hline 34 & 2.95 & 2.23 & 0.013 & $6,-41,-2$ \\
\hline 33 & 3.36 & 2.43 & 0.008 & $-26,-2,2$ \\
\hline 30 & 3.14 & 2.33 & 0.01 & $-38,-22,-2$ \\
\hline 29 & 2.31 & 1.89 & 0.03 & $-7,5,15$ \\
\hline 25 & 2.25 & 1.85 & 0.032 & $32,-9,-18$ \\
\hline 22 & 2.87 & 2.19 & 0.014 & $-26,2,27$ \\
\hline 21 & 3.31 & 2.41 & 0.008 & $-7,22,-2$ \\
\hline 21 & 2.39 & 1.93 & 0.027 & $-18,-46,2$ \\
\hline 19 & 2.58 & 2.04 & 0.021 & $-38,-26,-12$ \\
\hline 16 & 3.22 & 2.37 & 0.009 & $-21,-34,-4$ \\
\hline 14 & 2.6 & 2.05 & 0.02 & $-26,13,1$ \\
\hline 13 & 2.16 & 1.8 & 0.036 & $6,17,-5$ \\
\hline 12 & 3.12 & 2.32 & 0.01 & $37,-22,-10$ \\
\hline 12 & 2.44 & 1.96 & 0.025 & $32,-37,-14$ \\
\hline 11 & 2.16 & 1.79 & 0.036 & $-26,-6,9$ \\
\hline 10 & 2.49 & 1.99 & 0.023 & $-30,-53,-14$ \\
\hline \multicolumn{5}{|c|}{ Intransitive Observation $>$ Rest } \\
\hline \multirow[t]{3}{*}{979} & 9.46 & 3.95 & 0 & $21,-35,-7$ \\
\hline & 3.01 & 2.26 & 0.012 & $19,-48,-9$ \\
\hline & 2.53 & 2.01 & 0.022 & $11,-42,-7$ \\
\hline \multirow[t]{2}{*}{529} & 8.65 & 3.82 & 0 & $-38,-16,-11$ \\
\hline & 3.9 & 2.66 & 0.004 & $-37,-8,-6$ \\
\hline \multirow[t]{2}{*}{399} & 3.46 & 2.47 & 0.007 & $4,-7,9$ \\
\hline & 2.74 & 2.12 & 0.017 & $-5,-5,6$ \\
\hline \multirow[t]{2}{*}{311} & 6.05 & 3.31 & 0 & $-31,-33,-13$ \\
\hline & 3.24 & 2.37 & 0.009 & $-23,-22,-14$ \\
\hline \multirow[t]{3}{*}{302} & 3.62 & 2.54 & 0.006 & $0,13,-6$ \\
\hline & 2.93 & 2.22 & 0.013 & $-4,22,-4$ \\
\hline & 2.27 & 1.86 & 0.031 & $-2,11,2$ \\
\hline \multirow[t]{2}{*}{273} & 3.52 & 2.5 & 0.006 & $-12,-31,-8$ \\
\hline & 3.3 & 2.4 & 0.008 & $-10,-31,0$ \\
\hline 215 & 3.38 & 2.44 & 0.007 & $-33,3,14$ \\
\hline 204 & 3.11 & 2.31 & 0.01 & $-17,1,-2$ \\
\hline \multirow[t]{2}{*}{180} & 3.22 & 2.37 & 0.009 & $-3,-25,-2$ \\
\hline & 2.1 & 1.76 & 0.039 & $2,-18,0$ \\
\hline 177 & 4.24 & 2.78 & 0.003 & $15,-2,0$ \\
\hline 161 & 2.55 & 2.02 & 0.021 & $-6,-16,0$ \\
\hline \multirow[t]{2}{*}{159} & 3 & 2.26 & 0.012 & $27,-11,-19$ \\
\hline & 2.93 & 2.22 & 0.013 & $29,1,-14$ \\
\hline 136 & 3.11 & 2.31 & 0.01 & $22,14,2$ \\
\hline \multirow[t]{2}{*}{136} & 2.27 & 1.86 & 0.032 & $-9,14,-1$ \\
\hline & 2.9 & 2.21 & 0.014 & $\begin{array}{l}23,7,-2 \\
\text { (Table continues.) }\end{array}$ \\
\hline
\end{tabular}


Table 3. Continued

\begin{tabular}{|c|c|c|c|c|}
\hline Cluster size & $T$ & $Z$ & $p$ & $x, y, z(\mathrm{~mm})$ of peak $(\mathrm{s})$ \\
\hline 111 & 3.91 & 2.66 & 0.004 & $-26,11,9$ \\
\hline 108 & 5.24 & 3.1 & 0.001 & $20,-26,-7$ \\
\hline 107 & 3.39 & 2.44 & 0.007 & $-28,6,3$ \\
\hline 100 & 4.13 & 2.74 & 0.003 & $-26,12,1$ \\
\hline 92 & 2.67 & 2.09 & 0.018 & $-20,11,-1$ \\
\hline 48 & 2.51 & 2 & 0.023 & $-26,0,-6$ \\
\hline 35 & 2.67 & 2.09 & 0.018 & $-29,-13,1$ \\
\hline 31 & 3.71 & 2.58 & 0.005 & $27,5,2$ \\
\hline 31 & 2.85 & 2.19 & 0.014 & $-29,-48,-14$ \\
\hline 28 & 2.07 & 1.74 & 0.041 & $0,-16,6$ \\
\hline 25 & 2.09 & 1.75 & 0.04 & $37,-4,15$ \\
\hline 24 & 3.04 & 2.28 & 0.011 & $-29,-11,30$ \\
\hline 23 & 2.83 & 2.18 & 0.015 & $-26,-2,1$ \\
\hline 20 & 2.34 & 1.9 & 0.029 & $28,20,10$ \\
\hline 19 & 3.35 & 2.42 & 0.008 & $-32,-41,-14$ \\
\hline 19 & 2.59 & 2.05 & 0.02 & $-37,-22,1$ \\
\hline 17 & 2.52 & 2.01 & 0.022 & $6,-39,1$ \\
\hline 12 & 2.1 & 1.76 & 0.039 & $-25,-11,26$ \\
\hline 11 & 2.54 & 2.02 & 0.022 & $-14,-50,24$ \\
\hline 11 & 2.32 & 1.89 & 0.029 & $-27,-6,-21$ \\
\hline \multicolumn{5}{|c|}{ Execution $>$ Transitive Observation } \\
\hline \multirow[t]{2}{*}{469} & 5.77 & 3.24 & 0.001 & $-27,-35,23$ \\
\hline & 3.71 & 2.58 & 0.005 & $-31,-25,26$ \\
\hline \multirow[t]{2}{*}{444} & 10.28 & 4.06 & 0 & $6,18,3$ \\
\hline & 2.84 & 2.18 & 0.015 & $10,10,-2$ \\
\hline 225 & 5.07 & 3.05 & 0.001 & $-26,-18,10$ \\
\hline 207 & 4 & 2.69 & 0.004 & $37,-14,18$ \\
\hline 140 & 3.22 & 2.37 & 0.009 & $36,-26,16$ \\
\hline 127 & 6.37 & 3.39 & 0 & $6,-37,34$ \\
\hline 84 & 3.16 & 2.34 & 0.01 & $-5,-11,27$ \\
\hline 77 & 3.9 & 2.65 & 0.004 & $10,-22,22$ \\
\hline 69 & 3.92 & 2.66 & 0.004 & $12,-40,26$ \\
\hline 68 & 4.55 & 2.89 & 0.002 & $29,-5,8$ \\
\hline 64 & 4.97 & 3.02 & 0.001 & $-6,-12,10$ \\
\hline 49 & 4.73 & 2.95 & 0.002 & $-28,10,7$ \\
\hline 49 & 2.45 & 1.97 & 0.025 & $-23,-44,-10$ \\
\hline 47 & 3.03 & 2.28 & 0.011 & $-24,6,2$ \\
\hline 42 & 4.93 & 3.01 & 0.001 & $-5,-40,33$ \\
\hline 42 & 2.89 & 2.21 & 0.014 & $14,11,2$ \\
\hline 41 & 2.46 & 1.97 & 0.024 & $-38,-22,11$ \\
\hline 40 & 6.04 & 3.31 & 0 & $-28,-8,1$ \\
\hline 35 & 3.05 & 2.28 & 0.011 & $6,-54,1$ \\
\hline 21 & 4.83 & 2.98 & 0.001 & $-30,5,5$ \\
\hline 17 & 2.65 & 2.08 & 0.019 & $6,-28,30$ \\
\hline 17 & 2.26 & 1.86 & 0.032 & $39,-6,4$ \\
\hline 14 & 2.4 & 1.94 & 0.026 & $26,10,4$ \\
\hline 13 & 2.77 & 2.14 & 0.016 & $-33,-14,-6$ \\
\hline 13 & 2.36 & 1.92 & 0.028 & $-33,-34,20$ \\
\hline 11 & 2.32 & 1.89 & 0.029 & $-35,-20,17$ \\
\hline 10 & 2.53 & 2.01 & 0.022 & $-26,-25,19$ \\
\hline 10 & 2.24 & 1.84 & 0.033 & $-25,-49,-13$ \\
\hline \multicolumn{5}{|c|}{ Execution $>$ Intransitive Observation } \\
\hline \multirow[t]{2}{*}{930} & 4.45 & 2.85 & 0.002 & $-2,-18,34$ \\
\hline & 2.75 & 2.13 & 0.016 & $3,-11,24$ \\
\hline 508 & 5.36 & 3.13 & 0.001 & $-34,-23,21$ \\
\hline 271 & 8.04 & 3.72 & 0 & $7,14,3$ \\
\hline 260 & 6.87 & 3.5 & 0 & $30,10,14$ \\
\hline 234 & 7.22 & 3.57 & 0 & $9,-37,34$ \\
\hline \multirow[t]{2}{*}{212} & 5.51 & 3.18 & 0.001 & $10,6,-5$ \\
\hline & 3.97 & 2.68 & 0.004 & $14,10,2$ \\
\hline 174 & 3.82 & 2.62 & 0.004 & $2,12,21$ \\
\hline 132 & 3.52 & 2.5 & 0.006 & $-26,-17,10$ \\
\hline 129 & 3.21 & 2.36 & 0.009 & $-2,-29,28$ \\
\hline 92 & 5.99 & 3.3 & 0 & $\begin{array}{l}6,-2,6 \\
\text { (Table continues.) }\end{array}$ \\
\hline
\end{tabular}

Table 3. Continued

\begin{tabular}{|c|c|c|c|c|}
\hline Cluster size & $T$ & $Z$ & $p$ & $x, y, z(\mathrm{~mm})$ of peak(s) \\
\hline 79 & 7.13 & 3.55 & 0 & $26,-6,-3$ \\
\hline 75 & 5.91 & 3.28 & 0.001 & $-13,-43,13$ \\
\hline 75 & 2.83 & 2.17 & 0.015 & $5,-27,30$ \\
\hline 63 & 2.58 & 2.04 & 0.021 & $-19,-9,5$ \\
\hline 54 & 3.37 & 2.43 & 0.008 & $15,-47,24$ \\
\hline 53 & 4.07 & 2.72 & 0.003 & $7,-26,24$ \\
\hline 43 & 3.12 & 2.32 & 0.01 & $-6,-25,26$ \\
\hline 43 & 2.47 & 1.98 & 0.024 & $29,-2,8$ \\
\hline 42 & 3.61 & 2.53 & 0.006 & $6,-10,10$ \\
\hline 31 & 2.87 & 2.2 & 0.014 & $-2,10,26$ \\
\hline 28 & 3.87 & 2.64 & 0.004 & $-36,-29,18$ \\
\hline 28 & 2.79 & 2.15 & 0.016 & $21,10,1$ \\
\hline 27 & 3.02 & 2.27 & 0.012 & $-2,15,31$ \\
\hline 27 & 2.65 & 2.08 & 0.019 & $5,3,25$ \\
\hline 21 & 2.91 & 2.22 & 0.013 & $-14,-25,-1$ \\
\hline 21 & 2.44 & 1.96 & 0.025 & $29,13,2$ \\
\hline 19 & 2.5 & 2 & 0.023 & $2,-23,38$ \\
\hline 18 & 3.55 & 2.51 & 0.006 & $-37,-26,15$ \\
\hline 18 & 3.5 & 2.49 & 0.006 & $-29,17,3$ \\
\hline 18 & 2.41 & 1.94 & 0.026 & $-31,-8,12$ \\
\hline 17 & 5.46 & 3.16 & 0.001 & $-10,18,6$ \\
\hline 17 & 3.35 & 2.42 & 0.008 & $-2,4,22$ \\
\hline 15 & 3.64 & 2.55 & 0.005 & $14,-3,34$ \\
\hline 15 & 2.88 & 2.2 & 0.014 & $-32,13,14$ \\
\hline 14 & 2.63 & 2.07 & 0.019 & $14,31,17$ \\
\hline 13 & 3.29 & 2.4 & 0.008 & $-12,20,29$ \\
\hline 11 & 2.22 & 1.83 & 0.034 & $-23,-32,28$ \\
\hline 10 & 2.17 & 1.8 & 0.036 & $9,23,26$ \\
\hline 10 & 2.17 & 1.8 & 0.036 & $-23,-13,35$ \\
\hline \multicolumn{5}{|c|}{ Transitive Observation > Execution } \\
\hline \multirow[t]{3}{*}{1221} & 7.62 & 3.65 & 0 & $36,-20,0$ \\
\hline & 7.08 & 3.54 & 0 & $35,-30,-3$ \\
\hline & 4.14 & 2.74 & 0.003 & $29,-32,5$ \\
\hline 342 & 3.39 & 2.44 & 0.007 & $-2,-44,14$ \\
\hline 329 & 9.74 & 3.99 & 0 & $31,-49,-8$ \\
\hline 176 & 4.92 & 3.01 & 0.001 & $-24,22,9$ \\
\hline 168 & 4.89 & 2.99 & 0.001 & $-37,-22,-1$ \\
\hline \multirow[t]{2}{*}{159} & 7.96 & 3.71 & 0 & $-7,-24,0$ \\
\hline & 2.55 & 2.02 & 0.022 & $-10,-31,-6$ \\
\hline 129 & 4.58 & 2.9 & 0.002 & $2,-33,18$ \\
\hline 125 & 4.36 & 2.82 & 0.002 & $20,-35,-7$ \\
\hline 69 & 4.5 & 2.87 & 0.002 & $-4,-36,2$ \\
\hline 62 & 2.81 & 2.16 & 0.015 & $36,-41,-3$ \\
\hline 56 & 2.83 & 2.17 & 0.015 & $-26,2,27$ \\
\hline 43 & 2.65 & 2.08 & 0.019 & $30,4,24$ \\
\hline 39 & 3.55 & 2.51 & 0.006 & $18,-26,-6$ \\
\hline 32 & 2.45 & 1.96 & 0.025 & $-15,18,2$ \\
\hline 28 & 3.21 & 2.36 & 0.009 & $-2,-22,-9$ \\
\hline 26 & 3.21 & 2.36 & 0.009 & $-37,-6,15$ \\
\hline 25 & 5.79 & 3.25 & 0.001 & $-18,5,36$ \\
\hline 25 & 2.2 & 1.82 & 0.035 & $22,-22,-10$ \\
\hline 21 & 3.56 & 2.51 & 0.006 & $-34,-26,-13$ \\
\hline 20 & 2.48 & 1.98 & 0.024 & $-39,-28,-4$ \\
\hline 18 & 3.45 & 2.47 & 0.007 & $28,-39,14$ \\
\hline 17 & 2.26 & 1.86 & 0.032 & $-24,-56,8$ \\
\hline 16 & 2.73 & 2.12 & 0.017 & $-9,7,16$ \\
\hline 16 & 2.59 & 2.04 & 0.02 & $-6,17,30$ \\
\hline 15 & 2.4 & 1.94 & 0.026 & $-37,-16,-14$ \\
\hline 14 & 2.2 & 1.82 & 0.034 & $30,-13,-18$ \\
\hline 13 & 2.55 & 2.02 & 0.022 & $22,-58,-14$ \\
\hline 13 & 2.2 & 1.82 & 0.035 & $27,-20,-14$ \\
\hline 12 & 2.28 & 1.87 & 0.031 & $-34,10,14$ \\
\hline 11 & 2.17 & 1.8 & 0.036 & $-36,-32,4$ \\
\hline 10 & 2.96 & 2.24 & 0.013 & $\begin{array}{l}-23,-23,-13 \\
\text { (Table continues.) }\end{array}$ \\
\hline
\end{tabular}


Table 3. Continued

\begin{tabular}{|c|c|c|c|c|}
\hline Cluster size & $T$ & $Z$ & $p$ & $x, y, z(\mathrm{~mm})$ of peak $(\mathrm{s})$ \\
\hline 10 & 2.38 & 1.92 & 0.027 & $-32,-36,6$ \\
\hline 10 & 2.28 & 1.87 & 0.031 & $-37,-20,-13$ \\
\hline \multicolumn{5}{|c|}{ Intransitive Observation $>$ Execution } \\
\hline 364 & 4.99 & 3.03 & 0.001 & $-2,14,-3$ \\
\hline \multirow[t]{2}{*}{355} & 4.74 & 2.95 & 0.002 & $-3,-43,10$ \\
\hline & 2.25 & 1.85 & 0.032 & $2,-33,18$ \\
\hline \multirow[t]{2}{*}{204} & 3.76 & 2.6 & 0.005 & $31,-31,4$ \\
\hline & 3.52 & 2.5 & 0.006 & $33,-26,-4$ \\
\hline 143 & 4.28 & 2.79 & 0.003 & $30,-45,-10$ \\
\hline \multirow[t]{2}{*}{101} & 3.8 & 2.61 & 0.004 & $-20,27,10$ \\
\hline & 2.32 & 1.89 & 0.029 & $-17,18,4$ \\
\hline 88 & 4.16 & 2.75 & 0.003 & $-7,17,29$ \\
\hline 84 & 3.59 & 2.53 & 0.006 & $-9,34,16$ \\
\hline 53 & 2.59 & 2.05 & 0.02 & $27,-11,-19$ \\
\hline 46 & 3.65 & 2.55 & 0.005 & $-6,16,1$ \\
\hline 45 & 4.62 & 2.91 & 0.002 & $-5,-38,2$ \\
\hline 43 & 3.13 & 2.32 & 0.01 & $20,-35,-7$ \\
\hline 42 & 2.53 & 2.01 & 0.022 & $37,-3,12$ \\
\hline 40 & 2.5 & 2 & 0.023 & $10,-18,38$ \\
\hline 37 & 2.5 & 2 & 0.023 & $-29,5,-15$ \\
\hline 35 & 2.77 & 2.14 & 0.016 & $-9,-18,-1$ \\
\hline 30 & 2.92 & 2.22 & 0.013 & $-12,-29,-2$ \\
\hline 27 & 3.14 & 2.33 & 0.01 & $27,-4,26$ \\
\hline 25 & 2.95 & 2.23 & 0.013 & $-38,-22,0$ \\
\hline 23 & 2.79 & 2.16 & 0.016 & $-22,14,30$ \\
\hline 20 & 2.97 & 2.24 & 0.012 & $6,5,41$ \\
\hline 19 & 2.59 & 2.05 & 0.02 & $24,-35,27$ \\
\hline 14 & 2.7 & 2.11 & 0.018 & $-6,30,9$ \\
\hline 12 & 2.79 & 2.15 & 0.016 & $23,21,26$ \\
\hline 12 & 2.7 & 2.11 & 0.018 & $26,6,27$ \\
\hline 10 & 4.94 & 3.01 & 0.001 & $27,-11,18$ \\
\hline 10 & 3.14 & 2.33 & 0.01 & $25,-17,2$ \\
\hline \multicolumn{5}{|c|}{ Transitive $>$ Intransitive Observation } \\
\hline 179 & 4.29 & 2.8 & 0.003 & $-14,4,1$ \\
\hline \multirow[t]{2}{*}{170} & 5.13 & 3.07 & 0.001 & $-34,10,13$ \\
\hline & 3.59 & 2.53 & 0.006 & $-29,8,22$ \\
\hline \multirow[t]{2}{*}{155} & 6.25 & 3.36 & 0 & $35,-30,-3$ \\
\hline & 2.55 & 2.02 & 0.022 & $34,-22,-2$ \\
\hline 127 & 4.69 & 2.93 & 0.002 & $18,-6,38$ \\
\hline \multirow[t]{2}{*}{122} & 4.47 & 2.86 & 0.002 & $-33,-24,-13$ \\
\hline & 3.15 & 2.33 & 0.01 & $-36,-15,-14$ \\
\hline 113 & 4.97 & 3.02 & 0.001 & $-33,-24,21$ \\
\hline 109 & 2.91 & 2.22 & 0.013 & $22,-31,-10$ \\
\hline 54 & 2.34 & 1.9 & 0.029 & $7,29,4$ \\
\hline 49 & 3.66 & 2.56 & 0.005 & $-36,-30,17$ \\
\hline 42 & 5.54 & 3.18 & 0.001 & $13,9,-2$ \\
\hline 42 & 3.36 & 2.43 & 0.008 & $-14,18,2$ \\
\hline 36 & 3.3 & 2.4 & 0.008 & $33,-38,-2$ \\
\hline 29 & 4.5 & 2.87 & 0.002 & $6,14,2$ \\
\hline 29 & 2.86 & 2.19 & 0.014 & $23,-22,-11$ \\
\hline 27 & 2.76 & 2.14 & 0.016 & $-34,-9,-18$ \\
\hline 26 & 2.88 & 2.2 & 0.014 & $-2,-44,14$ \\
\hline 22 & 2.98 & 2.25 & 0.012 & $-25,-5,-19$ \\
\hline 21 & 4.7 & 2.94 & 0.002 & $-20,5,34$ \\
\hline 20 & 2.49 & 1.99 & 0.023 & $-21,-24,-6$ \\
\hline 18 & 3.23 & 2.37 & 0.009 & $-11,18,6$ \\
\hline 18 & 2.8 & 2.16 & 0.016 & $26,-42,-13$ \\
\hline 15 & 2.91 & 2.21 & 0.013 & $10,-40,33$ \\
\hline 15 & 2.5 & 2 & 0.023 & $33,-26,1$ \\
\hline 13 & 2.58 & 2.04 & 0.021 & $5,-29,25$ \\
\hline 12 & 2.64 & 2.07 & 0.019 & $26,-6,1$ \\
\hline 12 & 2.59 & 2.05 & 0.02 & $-16,-25,-2$ \\
\hline 12 & 2.5 & 2 & 0.023 & $34,-31,-12$ \\
\hline 12 & 2.5 & 1.99 & 0.023 & $\begin{array}{l}6,17,25 \\
\text { (Table continues.) }\end{array}$ \\
\hline
\end{tabular}

Table 3. Continued

\begin{tabular}{clllc}
\hline Cluster size & $T$ & $Z$ & $p$ & $x, y, z(\mathrm{~mm})$ of peak $(\mathrm{s})$ \\
\hline 12 & 2.23 & 1.84 & 0.033 & $20,22,7$ \\
11 & 2.43 & 1.96 & 0.025 & $-31,-19,-9$ \\
10 & 2.16 & 1.8 & 0.036 & $-1,16,30$ \\
Intransitive > Transitive Observation & & & & \\
51 & 2.62 & 2.06 & 0.02 & $-27,-7,-6$ \\
49 & 5.59 & 3.2 & 0.001 & $28,-8,17$ \\
45 & 3.83 & 2.63 & 0.004 & $27,-7,7$ \\
38 & 3.15 & 2.33 & 0.01 & $-6,-47,18$ \\
33 & 2.52 & 2.01 & 0.022 & $-7,-4,7$ \\
32 & 6.62 & 3.44 & 0 & $-31,-14,-5$ \\
29 & 2.33 & 1.9 & 0.029 & $13,-2,4$ \\
24 & 4.14 & 2.74 & 0.003 & $-29,10,8$ \\
16 & 2.67 & 2.09 & 0.018 & $-24,-37,25$ \\
15 & 3.41 & 2.45 & 0.007 & $25,-34,28$ \\
14 & 2.68 & 2.1 & 0.018 & $-35,-10,-11$ \\
12 & 2.26 & 1.85 & 0.032 & $-2,-39,31$ \\
\hline
\end{tabular}

tion conditions activated visibly similar regions, both when considering group-level activations compared with a low-actionexecution, low-action-perception rest condition (Figs. $4 B, C$, $5 B, C)$ and when considering conservatively thresholded individual subject-level activations without a comparison condition (Fig. 6, Transitive and Intransitive Observation panels for each subject).

To identify brain regions that mapped observed actions onto the same substrates used to perform them, we performed a conjunction analysis, selecting voxels that were active in both the execution and transitive or intransitive observation conditions. The final two panels for each chimpanzee in Figure 6 shows these overlaps in individual subjects; Figure $7 D, E$ show $3 D$ renderings of a group composite map; Figure $8 D, E$ show coronal slices of this group composite map. Regions of overlap between execution and transitive action observation included central sulcus, precentral and postcentral gyri, dorsal and ventral premotor cortex, ventrolateral prefrontal cortex, dorsolateral prefrontal cortex, and inferior and superior parietal cortex. Regions of overlap between execution and intransitive action observation are visibly very similar, both at the individual subjects level (Fig. 6, Execution U Transitive/Instransitive Observation panels for each subject) and at the group level (Figs. $7 D, E, 8 D, E$ ).

\section{ROI analyses}

Finally, we compared the ratio of the frontal and parietal ROI's volumes that contained above-threshold activation, both in the individual conditions and in the Execution U Transitive/Intransitive Observation conjunction analyses. Activity in both the frontal and parietal ROIs was significantly greater in each of the experimental conditions than in the rest condition, but there was no significant difference between the Transitive and the Intransitive Observation conditions (Fig. 9A). Similarly, activity in the ROIs was not significantly different between the Execution $U$ Transitive Observation and Execution U Intransitive Observation conjunction analyses (Fig. 9B).

\section{Comparison of chimpanzee and human grasping observation networks}

Whole-brain analyses

Figure 10 shows the top $1 \%$ of activation in the transitive observation condition for each of six human subjects, as well as composite group image of these activations rendered on the MNI template. The individual thresholded images in Figure $10 \mathrm{~A}$ are comparable to the chimpanzee Transitive Observation panels in 
Figure 6; the composite group image is comparable to the chimpanzee image in Figure $7 B$. Differences between chimpanzee and human activations are grossly evident. Chimpanzee activation is focused mainly in frontal cortex, including especially prefrontal cortex, with relatively less activation in occipitotemporal and parietal cortex. In contrast, human activation is more evenly distributed between frontal, parietal, and occipitotemporal cortex.

\section{ROI analyses}

To assess these qualitative differences quantitatively, we measured the proportion of the total volume of abovethreshold activation that fell into each of a set of ROIs drawn in homologous regions of human and chimpanzee frontal, parietal, and occipitotemporal cortex. These ROIs are illustrated in Figure $11 A$ and are anatomically defined in Table 2 . This comparison revealed significantly greater activation in ventrolateral prefrontal cortex in chimpanzees and greater activation in ventral premotor cortex, inferior parietal lobule, and inferotemporal cortex in humans (Fig. 11B).

\section{Discussion}

This research characterized the responses of the chimpanzee action execution/observation system. We identified chimpanzee regions that were activated during performance of object-directed grasping, observation of the same action, and observation of similar movements performed without grasping any object. Group-level statistical comparisons between each of these conditions and rest highlighted small, focused activations in the hemisphere contralateral to the hand carrying out the task (Figs. 4, 6); conservatively thresholded scans in individual subjects revealed a distributed bilateral network (Figs. 6, 7, 8). Chimpanzee regions that are more activated by producing than observing grasping include portions of inferior parietal cortex, including anterior intraparietal sulcus and probably the chimpanzee homolog of area AIP, somatosensory cortex, cerebellum, and premotor cortex (Figs. 4D,E, 5D,E). Chimpanzee regions that are more activated by observing than producing grasping include portions of superior temporal sulcus, inferotemporal cortex, occipitotemporal cortex, and inferior frontal gyrus (Figs. $4 F, G, 5 F, G)$. These results are, unsurprisingly, similar to activations reported in macaques and humans (for review, see (Orban and Jastorff, 2013).

An important result of these analyses was that chimpanzee brain activations for

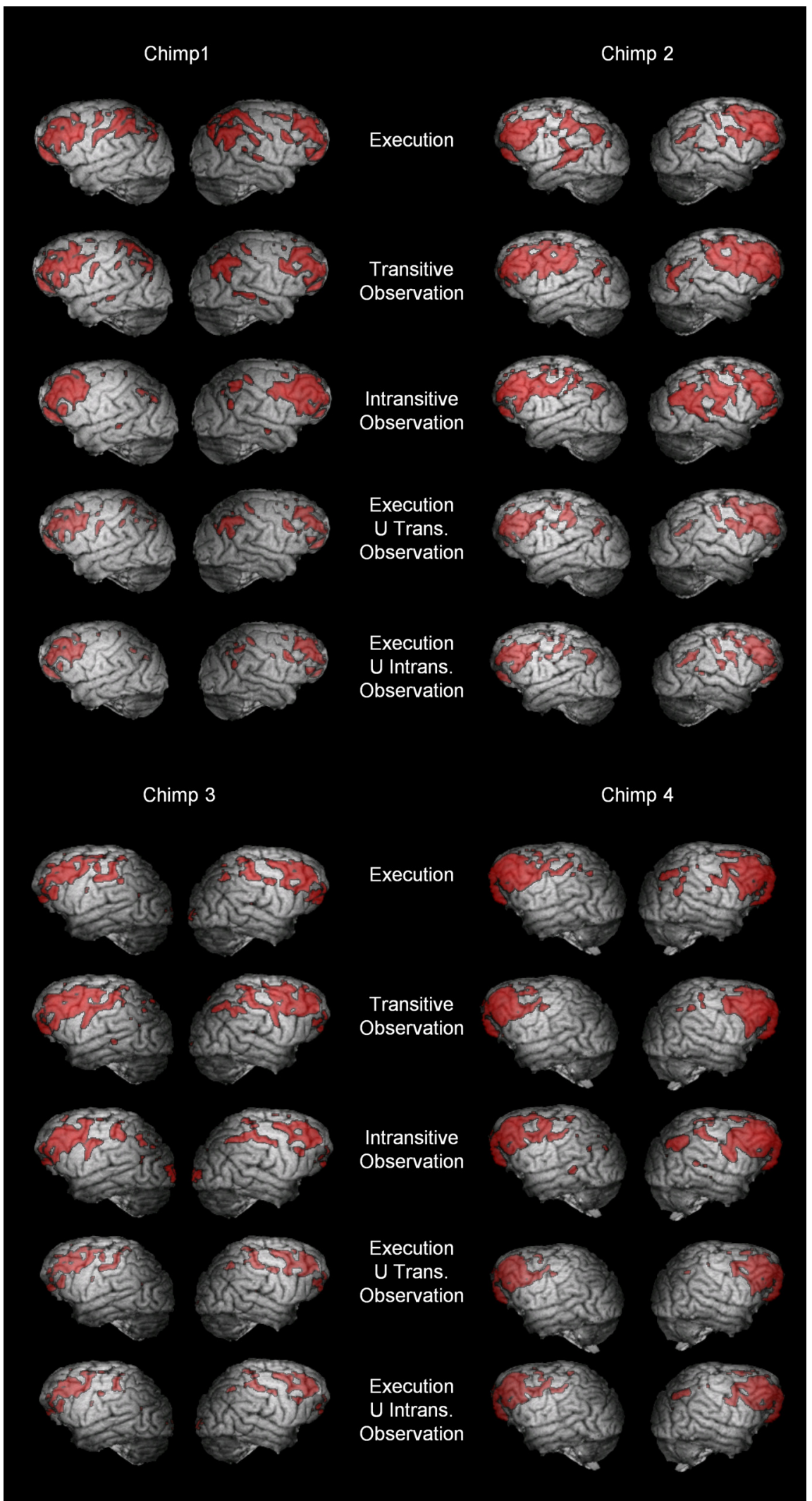

Figure 6. 3D surface renderings of top $1 \%$ of activity in chimpanzee subjects during each individual condition and in conjunction analyses. Left hemispheres appear on the left. 


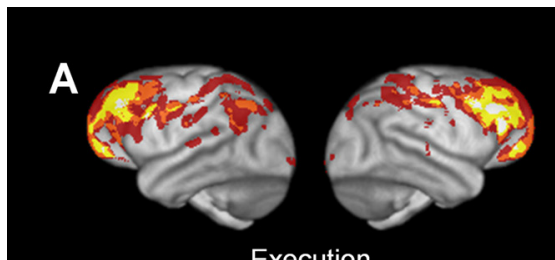

Execution

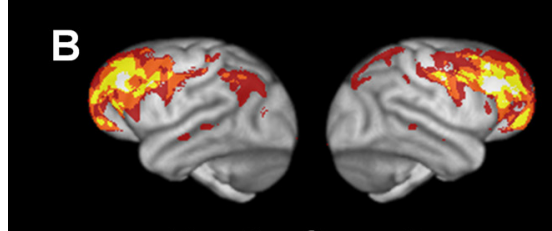

Transitive Observation

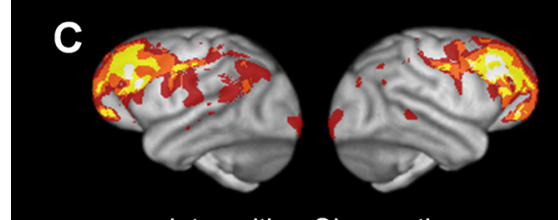

Intransitive Observation

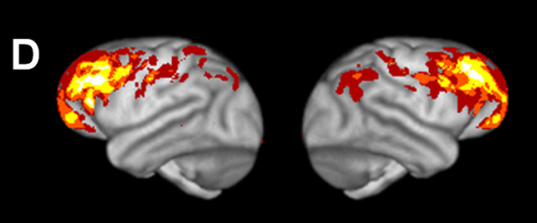

Execution U Transitive Observation

E

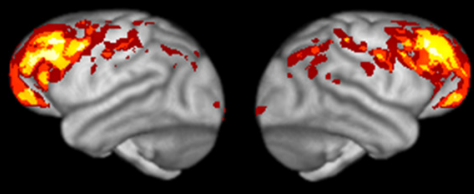

Execution U Intransitive observation

Overlap of above-threshold activation across subjects

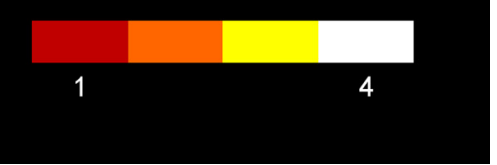

Figure 7. 3D surface renderings of overlap of above-threshold activation across chimpanzee subjects in individual conditions and in conjunction analyses. Left hemispheres appear on the left. $\boldsymbol{A}$, Execution. $\boldsymbol{B}$, Transitive Observation. $\boldsymbol{C}$, Intransitive Observation. $\boldsymbol{D}$, Voxels activated above threshold in both Execution and Transitive Observation. $\boldsymbol{E}$, Voxels activated above threshold in both Execution and Intransitive Observation.

observing transitive and intransitive actions are very similar (Fig. 5). There are a few small, constrained portions of chimpanzee frontoparietal cortex that are activated more by transitive than intransitive observation (Figs. $4 \mathrm{H}, 5 \mathrm{H}$ ), but the regions of overlap between execution and transitive observation are nearly identical to the regions of overlap between execution and intransitive observation (Figs. $7 D, E, 8 D, E$ ). Furthermore, in ROIs homologous to macaque regions that contain mirror neurons, there is no significant difference in activation for transitive and intransitive observation (Fig. 9). This suggests that when a chimpanzee observes another individual performing hand movements, these are mapped onto almost the same brain regions that the chimp would use to produce those movements himself regardless of whether the movements lead to a physical result. This is similar to humans, who also map observed intransitive actions onto one's own motor system with somatotopic specificity (Buccino et al., 2001; Binkofski and Buccino, 2006; Filimon et al., 2007; Lui et al., 2008). This result is in notable contrast to macaques, in which mirror neurons are strongly goal oriented (Umiltà et al., 2001) and do not respond to intransitive action (Rizzolatti et al., 1996).

What might be the behavioral significance of chimpanzees' similar neural responses for transitive and intransitive action? Lyons et al. (2006) proposed that the macaque brain performs "intentional compression," boiling observed actions down to their environmental results. Our results suggest that the chimpanzee brain does not "compress" observed actions in this way. Chimpanzees map not only the results but also the movements of observed actions to the same brain regions that produce those actions. This may be a correlate of, and a prerequisite to, the ability to copy specific movements. Perhaps for an individual to copy the specific movements of an action, the brain must be capable of mapping those movements onto the same neural circuitry used to produce them. Therefore, perhaps macaques emulate results but do not imitate movements because their brains "mirror" interactions between hands and objects, but not manual

movements apart from objects. Perhaps chimpanzees are capable of some limited imitation of movements because their brains, like ours, do "mirror" movements. This hypothesis could be investigated in other species that copy the specific movements of observed actions.

We also found that chimpanzee FCBm, the homolog to human BA 44, is more responsive to grasping actions than $\mathrm{PFD} / \mathrm{PF}$, which is homologous to human BA 40 (Fig. 9A,B). This is similar to macaque 2-deoxyglucose studies in which observing grasping action caused signal increases between 7\% and 19\% in F5 and between $2 \%$ and $11 \%$ in PF/PFG (Raos et al., 2004; 2007). This is also similar to macaque fMRI studies finding greater frontal activation and reduced parietal activation compared with humans during the perception of actions and objects (Vanduffel et al., 2002; Denys et al., 2004; Raos et al., 2004; 2007; Peeters et al., 2009). In contrast, meta-analyses of $>100$ human fMRI and $\mathrm{O}^{15}$ PET studies have reported comparatively more balanced frontal and parietal activations (Caspers et al., 2010; Molenberghs et al., 2012).

Our human FDG-PET study enabled a direct comparison with our chimpanzee activations. Differences in activation were grossly evident. Chimpanzee activation was focused mainly in frontal cortex, including especially prefrontal cortex, with relatively less activation in occipitotemporal and parietal cortex. In contrast, human activation was more evenly distributed among frontal, parietal, and occipitotemporal cortex (compare Transitive Observation panels in Figs. 6, 10). Quantitatively, chimpanzees had significantly more activation in ventrolateral prefrontal cortex, whereas humans had significantly more activation in inferior parietal cortex, inferotemporal cortex, and ventral premotor cortex (Fig. 11).

A limitation of the present study was that behavioral conditions and scan acquisition methods were not identical for chimpanzees and humans. This was because the human data were acquired as pilot data for a separate study. Due to the rarity of chimpanzee data and the even greater rarity of comparable human data, we performed opportunistic post hoc comparisons. Our analyses carefully controlled for methodological differences and, importantly, expectations for possible methodology-related differences in regional brain activation are opposite to what we observed, suggesting that observed differences in brain activation were not due to these methodological differences (Table 4). Further research is warranted to more precisely delineate chimpanzee/human differences, particularly during the observation of intransitive action.

Our results indicate that the neural response of chimpanzees to the observation of object-directed grasping is biased toward prefrontal cortex in a way that the response of humans is not. Conversely, the neural response of humans is biased toward parietal and occipitotemporal regions in a way that the response of chimpanzees is not. To be clear, there is abundant evidence of occipitotemporal and parietal response to transitive action observation in macaques and humans (for review, see Orban and Jastorff, 2013), and our data do indicate such responses in 
chimpanzees as well (Figs. 4, 7). The novel finding of the present report is a difference in the relative distribution of neural activity. These results are consistent with our recent analysis of white matter connectivity among inferior frontal, inferior parietal, and lateral temporal regions, in which more tractography streamlines reached further into parietal and lateral temporal cortex in humans than in chimpanzees or macaques (Hecht et al., 2013). These differences in white matter connectivity parallel, and could underlie, the differences in activation.

Our results suggest that the chimpanzee neural architecture for action and object perception is more similar to macaques than to humans. Macaques' and chimpanzees' frontal bias for action and object perception may represent the ancestral condition, whereas humans' parietal/ occipitotemporal bias may represent a relatively recent adaptation. Macaques, chimpanzees, and humans shared a last common ancestor $\sim 25$ million years ago (MYA), whereas the chimpanzee-human last common ancestor existed much more recently, approximately 6 MYA (Goodman et al., 1998). However, major events in hominid evolution related to object-directed action occurred after this split: our hominin ancestors' hands became more available for object manipulation with the emergence of bipedalism 3-6 MYA (for review, see Harcourt-Smith and Aiello, 2004) and the earliest known intentionally modified stone tools appeared $\sim 2.6$ MYA (Semaw et al., 2003), whereas more complex stone tools emerged only 1.7-0.5 MYA (for review, see Stout, 2011).

What might be the functional and behavioral implications of these neural differences? Action understanding in humans and macaques relies on multiple levels of information processing in a tightly integrated network of functionally specialized frontal, parietal, and occipitotemporal regions. Although the precise functional contributions of each region across species remain to be resolved, there is substantial evidence that, compared with ventral premotor cortex and postcentral regions, ventrolateral prefrontal cortex supports more abstract action representations such as context, outcomes, and intentions (Rizzolatti et al., 1988; Nelissen et al., 2005; Hamilton and Grafton, 2008; Bonini et al., 2010) and/or top-down cognitive control processes such as rule-based action selection, information retrieval, and hierarchical control (Petrides, 2005; Koechlin and Jubault, 2006; Badre and D'Esposito, 2009). Conversely, occipitotemporal and parietal regions have been associated with

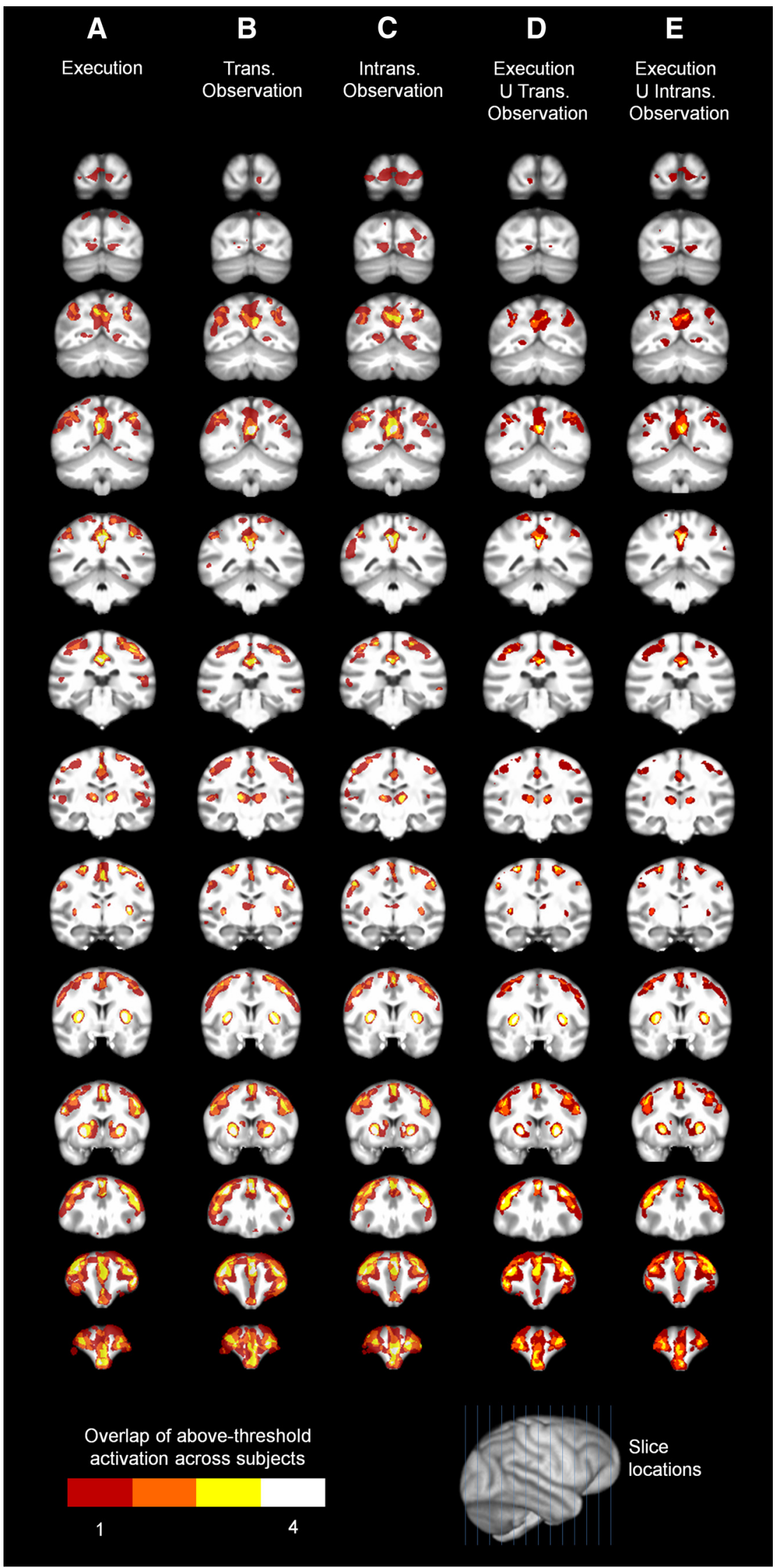

Figure 8. Cortical lices of overlap of above-threshold activation across chimpanzeesubjects in individual conditions and in conjunctionanalyses. Lefthemispheres appear on the left.A, Execution. $\boldsymbol{B}$, Transitive Observation. C, Intransitive Observation. $\boldsymbol{D}$, Voxels activated above threshold in both Execution and Transitive 0 bservation. $E$, Voxels activated above threshold in both Execution and Intransitive 0 bservation. 
A

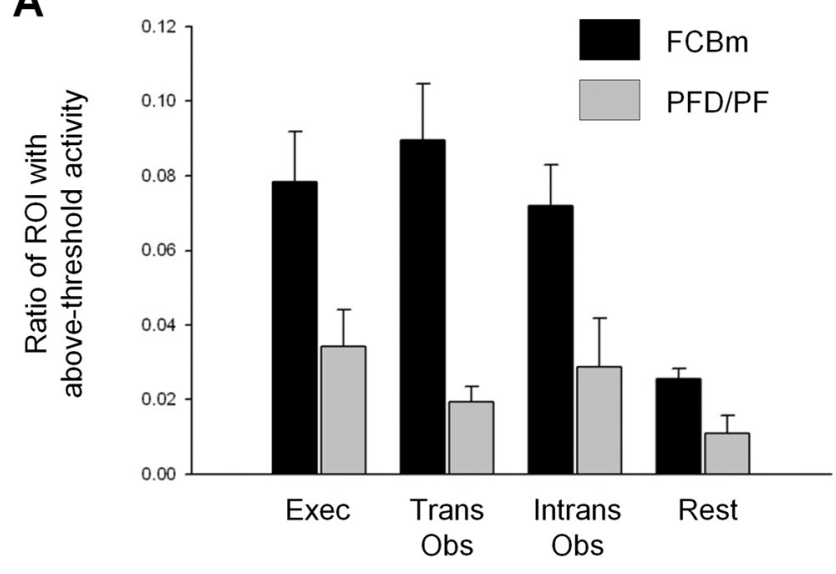

B

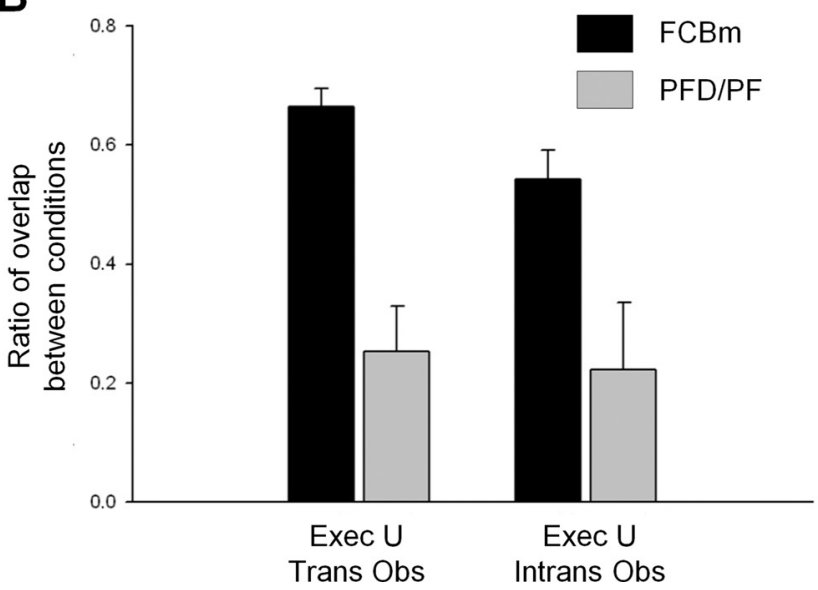

Figure 9. Quantification of activity in chimpanzee regions homologous to those that contain mirror neurons in macaques. $A, \mathrm{RO}$ activation in individual conditions. Percentage of ROIs active in each condition were averaged across subjects. An initial repeated-measures ANOVA showed no effect of hemisphere, so data were averaged bilaterally for each ROI. Activation was greater in execution, transitive observation, and intransitive observation relative to rest, as measured with a repeated-measures ANOVA (main effect of task condition, $F_{(3,9)}=14.185, p<0.001$; individual comparisons, $p=0.004,0.007$, and 0.026 , respectively). In addition, the FCBm was more active than PFD/PF (main effect of region, $F_{(1,3)}=17.386, p=0.014$ ). $\boldsymbol{B}$, ROl activation in conjunction analyses. Percentage of voxels in top $1 \%$ of execution condition which were also in top $1 \%$ of transitive observation or intransitive observation conditions in FCMb and PF, averaged across subjects. A repeated-measures ANOVA revealed no effect of condition, but a main effect of region $\left(F_{(1,3)}=16.076, p=0.028\right)$; the frontal $\mathrm{ROI}$ was more active than the parietal ROI.

more specific representations, such as kinematics or proximate goals (Rozzi et al., 2008; Bonini et al., 2010) and/or bottom-up perceptualmotor processes such as recognition, categorization, and sequencing (Jubault et al., 2007; Jastorff et al., 2010), including the integration of semantic and motor information for complex tool use (Frey, 2007). The observed prefrontal bias in chimpanzee brain response during transitive action observation thus suggests greater functional investment in high-level representations and topdown control processes, compared with a human condition displaying relatively greater reliance on specific representations and bottom-up perceptual recognition. This functional difference parallels behavioral evidence. When copying others' behavior, humans have a greater propensity for copying action details (imitating), whereas chimpanzees have a greater propensity for copying action outcomes (emulating) (Whiten et al., 2009). Similarly, when monitoring their own behavior,

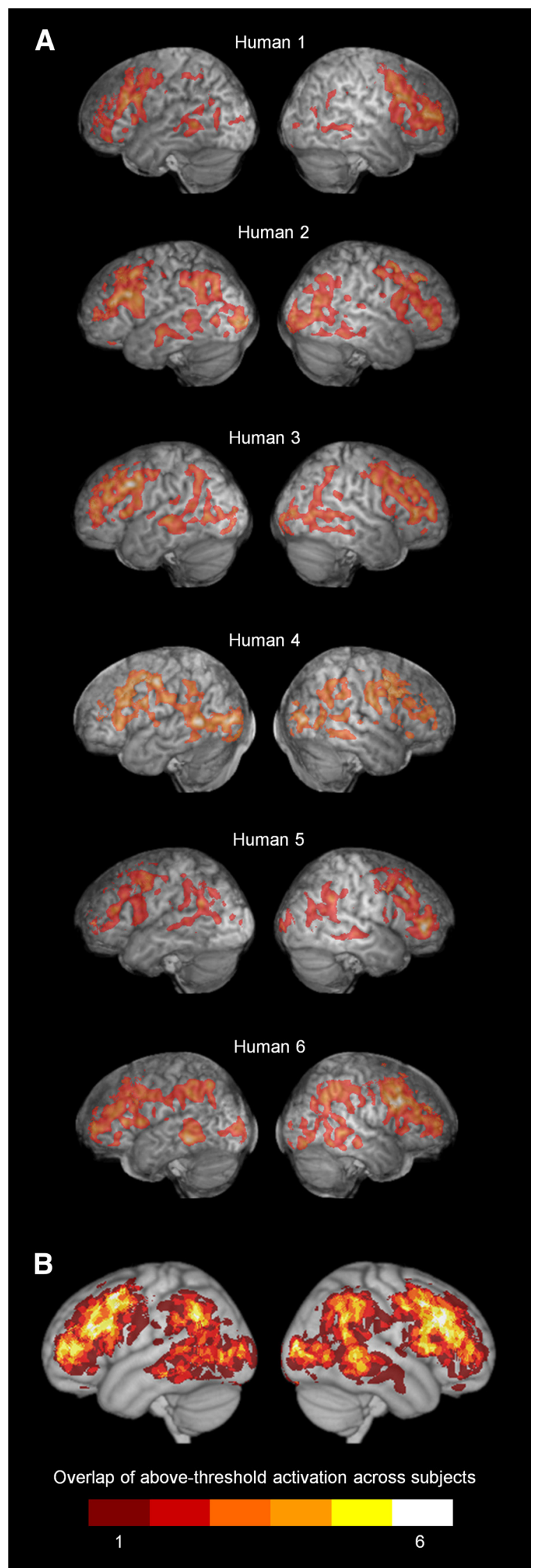

Figure 10. Human activation during transitive grasping observation. Left hemispheres appear on the left. $\boldsymbol{A}$, Top $1 \%$ of activity in individual subjects. $\boldsymbol{B}$, Overlap of above-threshold activation across subjects. 


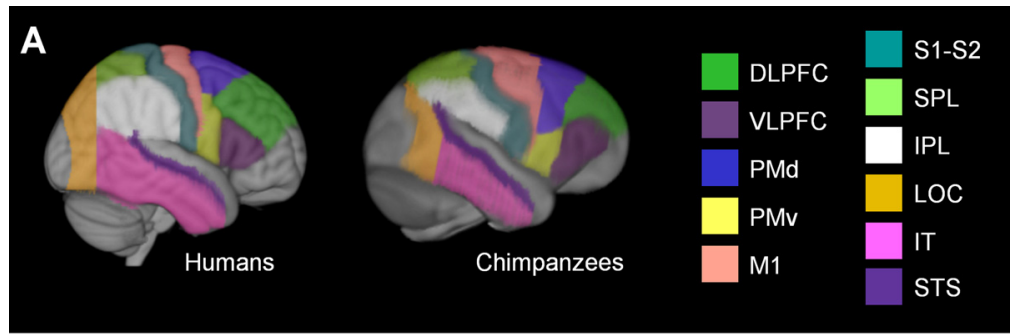

B

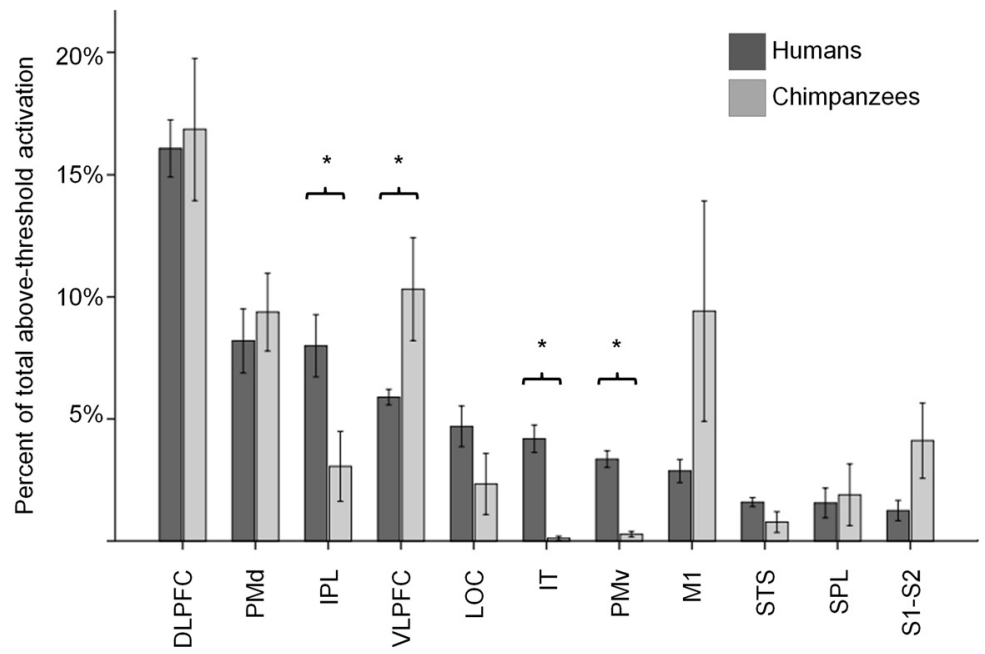

Figure 11. Quantitative comparison of chimpanzee and human activation during transitive grasping observation. $\boldsymbol{A}$, ROIs. B, Percentage of total above-threshold activation that fell into each ROI. Inferior parietal lobule (IPL), inferotemporal cortex (IT), and PMv accounted for a significantly greater proportion of overall activation in humans than in chimpanzees ( $p=0.036, p<0.001$, and $p<0.001$, respectively; independent samples $t$ test). Ventrolateral prefrontal cortex (VLPFC) accounted for a significantly greater proportion of overall activation in chimpanzees than in humans $(p=0.033$, independent samples $t$ test). Error bars, \pm 1 SEM. DLPFC, dorsolateral prefrontal cortex; PMd, dorsal premotor cortex; PMv, ventral premotor cortex; $M 1$, primary motor cortex; $\mathrm{S} 1-\mathrm{S} 2$, primary and secondary somatosensory cortex; $L O C$, lateral occipital cortex; STS, superior temporal sulcus.

humans have a bias toward monitoring kinematics, whereas chimpanzees have a bias toward monitoring goals (Kaneko and Tomonaga, 2012). Humans' increased attention to their own and others' action details has been identified as a key factor in the emergence of imitation, cumulative culture, and the complex object-related behaviors they enable (Tennie et al., 2009; Dean et al., 2012); the results reported here offer a window into the neural and cognitive bases of these adaptations.

\section{References}

Badre D, D’Esposito M (2009) Is the rostro-caudal axis of the frontal lobe hierarchical? Nat Rev Neurosci 10:659-669. CrossRef Medline

Bailey P (1948) Concerning cytoarchitecture of the frontal lobe of chimpanzee (Pan satyrus) and man (Homo sapiens). In: The frontal lobes (Fulton JF, ed), pp 84-94 Baltimore: Williams and Wilkins.

Bailey P, Von Bonin G, McCulloch W (1950) The isocortex of the chimpanzee. Urbana, Illinois: The University of Illinois.

Binkofski F, Buccino G (2006) The role of ventral premotor cortex in action execution and action understanding. J Physiol Paris 99:396-405. CrossRef Medline

Bonini L, Rozzi S, Serventi FU, Simone L, Ferrari PF, Fogassi L (2010) Ventral premotor and inferior parietal cortices make distinct contribution to action organization and intention understanding. Cereb Cortex 20:1372-1385. CrossRef Medline

Brodmannn K (1909) Vergleichende Lokalisationslehre der Grosshirnrhinde. Leipzig: Barth (reprinted as Brodmannn's Localisation in the Cereb Cortex, translated and edited by L. J. Garey, London: SmithGordon, 1994).
Buccino G, Binkofski F, Fink GR, Fadiga L, Fogassi L, Gallese V, Seitz RJ, Zilles K, Rizzolatti G, Freund HJ (2001) Action observation activates premotor and parietal areas in a somatotopic manner: an fMRI study. Eur J Neurosci 13:400-404. CrossRef Medline

Caggiano V, Fogassi L, Rizzolatti G, Pomper JK, Thier P, Giese MA, Casile A (2011) Viewbased encoding of actions in mirror neurons of area $\mathrm{f} 5$ in macaque premotor cortex. Curr Biol 21:144-148. CrossRef Medline

Caspers S, Zilles K, Laird AR, Eickhoff SB (2010) ALE meta-analysis of action observation and imitation in the human brain. Neuroimage 50:1148-1167. CrossRef Medline

Clark A (2008) Supersizing the mind: embodiment, action, and cognitive extension. New York: Oxford UP

Dean LG, Kendal RL, Schapiro SJ, Thierry B, Laland KN (2012) Identification of the social and cognitive processes underlying human cumulative culture. Science 335:1114-1118. CrossRef Medline

Denys K, Vanduffel W, Fize D, Nelissen K, Sawamura H, Georgieva S, Vogels R, Van Essen D, Orban GA (2004) Visual activation in prefrontal cortex is stronger in monkeys than in humans. J Cogn Neurosci 16:1505-1516. CrossRef Medline

Economo C, Parker S (1929) The cytoarchitectonics of the human cerebral cortex. London: Humphrey Milford; Oxford UP.

Filimon F, Nelson JD, Hagler DJ, Sereno MI (2007) Human cortical representations for reaching: mirror neurons for execution, observation, and imagery. Neuroimage 37:1315-1328. CrossRef Medline

Frey SH (2007) What puts the how in where? Tool use and the divided visual streams hypothesis. Cortex 43:368-375. CrossRef Medline

Georgieva S, Peeters R, Kolster H, Todd JT, Orban GA (2009) The processing of three-dimensional shape from disparity in the human brain. J Neurosci 29:727-742. CrossRef Medline

Goodall J (1964) Tool-using and aimed throwing in a community of freeliving chimpanzees. Nature 201:1264-1266. CrossRef Medline

Goodman M, Porter CA, Czelusniak J, Page SL, Schneider H, Shoshani J, Gunnell G, Groves CP (1998) Toward a phylogenetic classification of primates based on DNA evidence complemented by fossil evidence. Mol Phylogenet Evol 9:585-598. CrossRef Medline

Hamilton AF, Grafton ST (2008) Action outcomes are represented in human inferior frontoparietal cortex. Cereb Cortex 18:1160-1168. Medline

Harcourt-Smith WE, Aiello LC (2004) Fossils, feet and the evolution of human bipedal locomotion. J Anat 204:403-416. CrossRef Medline

Hecht EE, Gutman DA, Preuss TM, Sanchez MM, Parr LA, Rilling JK (2013) Process versus product in social learning: comparative diffusion tensor imaging of neural systems for action executionobservation matching in macaques, chimpanzees, and humans. Cereb Cortex 23:1014-1024. CrossRef Medline

Iacoboni M, Woods RP, Brass M, Bekkering H, Mazziotta JC, Rizzolatti G (1999) Cortical mechanisms of human imitation. Science 286:25262528. CrossRef Medline

Iriki A, Sakura O (2008) The neuroscience of primate intellectual evolution: natural selection and passive and intentional niche construction. Philos Trans R Soc Lond B Biol Sci 363:2229-2241. CrossRef Medline

Jastorff J, Begliomini C, Fabbri-Destro M, Rizzolatti G, Orban GA (2010) Coding observed motor acts: different organizational principles in the parietal and premotor cortex of humans. J Neurophysiol 104:128 140. CrossRef Medline

Joly O, Vanduffel W, Orban GA (2009) The monkey ventral premotor 
Table 4. Evaluation of the potential effects of differences in methodology in human versus chimpanzee experiments

\begin{tabular}{|c|c|c|}
\hline Difference between human and chimpanzee experiments & $\begin{array}{l}\text { Expected result if this difference is great enough to } \\
\text { significantly affect the pattern of brain activation }\end{array}$ & Evaluation of data \\
\hline $\begin{array}{l}\text { Humans received intravenous, } 10 \text { mCi doses of fluorode- } \\
\text { oxyglucose, whereas chimpanzees received oral, } 15 \\
\text { mCi doses. }\end{array}$ & $\begin{array}{l}\text { This might cause differences in the overall level of activity } \\
\text { across the brain (i.e., human scans might have greater } \\
\text { absolute brightness). }\end{array}$ & $\begin{array}{l}\text { Each scan was normalized to its own mean intensity } \\
\text { value, so the average intensity of each image is } \\
\text { exactly equal to 1. Identical thresholding meth- } \\
\text { ods were applied to both species. Above-thresh- } \\
\text { old voxels in each Rol were normalized as a } \\
\text { percentage of the total above-threshold voxels in } \\
\text { the entire brain. These steps control for possible } \\
\text { differences in the overall level of brain activity. }\end{array}$ \\
\hline $\begin{array}{l}\text { Human stimuli were } 2 \mathrm{D} \text { videos, whereas chimpanzee } \\
\text { stimuli were } 3 \mathrm{D} \text { live demonstrations. }\end{array}$ & $\begin{array}{l}\text { PMv is involved in processing 3D shape from visual dis- } \\
\text { parity (stereopsis) (Georgieva et al., 2009; Joly et al., } \\
\text { 2009). This might cause greater PMv activation in } \\
\text { chimpanzees than humans. In addition, a lower per- } \\
\text { centage of macaque mirror neurons are activated by } \\
\text { videos than by live demonstrations (Cagaiano et al }\end{array}$ & $\begin{array}{l}\text { Humans had greater activation than chimpanzees in } \\
\text { both ventral premotor cortex and inferior pari- } \\
\text { etal cortex. This suggests that species differences } \\
\text { in the pattern of brain activation are not due to } \\
\text { differences in the dimensionality of the stimuli. }\end{array}$ \\
\hline
\end{tabular}

2011). This might cause greater chimpanzee activation in regions homologous to those that contain mirror neurons in macaques.

In monkeys, observation of only a hand grasping an object activates more rostral regions of VLPFC and PMv (areas 46, 45A, 45B, and rostral F5), whereas observation of an entire demonstrator grasping an object also activates caudal F5 (Nelissen et al., 2005). This might cause frontal activations to extend more caudally than in chimpanzees than humans.

Observed reaching activates more dorsal regions of premotor cortex than observed grasping (Filimon et al., 2007). This might cause greater PMd activation in humans than chimpanzees.
Chimpanzee stimuli included a more prominent reaching action than human stimuli.
Human stimuli consisted only of a hand, the lower porwhereas tabletop, and graspable object, man demonstrator as well as the testing box in which the grasping actions were performed.
Frontal activations extended more caudally in humans than chimpanzees; PMv contained a significantly greater proportion of total brain activation in humans than chimpanzees (Figure 11). This suggests that species differences in the pattern of brain activation are not due to differences in scene complexity.

PMd activation was not significantly different between humans and chimpanzees (Figure 11). This suggests that species differences in the pattern of brain activation are not due to differences in the prominence of the observed reaching action.

Possible methodology-related differences in regional brain activation were either controlled for using normalization procedures or are opposite to what we observed; therefore, these differences are not likely to have contributed to differences in observed activation.

PMv, ventral premotor cortex; PMd, dorsal premotor cortex; VLPFC, ventrolateral prefrontal cortex; IPL, inferior parietal lobule.

cortex processes 3D shape from disparity. Neuroimage 47:262272. CrossRef Medline

Jubault T, Ody C, Koechlin E (2007) Serial organization of human behavior in the inferior parietal cortex. J Neurosci 27:11028-11036. CrossRef Medline

Kaneko T, Tomonaga M (2012) Relative contributions of goal representation and kinematic information to self-monitoring by chimpanzees and humans. Cognition 125:168-178. CrossRef Medline

Koechlin E, Jubault T (2006) Broca's area and the hierarchical organization of human behavior. Neuron 50:963-974. CrossRef Medline

Li L, Preuss TM, Rilling JK, Hopkins WD, Glasser MF, Kumar B, Nana R, Zhang X, Hu X (2010) Chimpanzee (Pan troglodytes) precentral corticospinal system asymmetry and handedness: a diffusion magnetic resonance imaging study. PloS One 5:e12886. CrossRef Medline

Lui F, Buccino G, Duzzi D, Benuzzi F, Crisi G, Baraldi P, Nichelli P, Porro CA, Rizzolatti G (2008) Neural substrates for observing and imagining nonobject-directed actions. Soc Neurosci 3:261-275. CrossRef Medline

Lyons DE, Santos LR, Keil FC (2006) Reflections of other minds: how primate social cognition can inform the function of mirror neurons. Curr Opin Neurobiol 16:230-234. CrossRef Medline

Molenberghs P, Cunnington R, Mattingley JB (2012) Brain regions with mirror properties: a meta-analysis of 125 human fMRI studies. Neurosci Biobehav Rev 36:341-349. CrossRef Medline

Nelissen K, Luppino G, Vanduffel W, Rizzolatti G, Orban GA (2005) Observing others: multiple action representation in the frontal lobe. Science 310:332-336. CrossRef Medline

Orban G, Jastorff J (2013) Functional mapping of motion regions in humans and non-human primates. In: The new visual neurosciences (Werner J, Chalupa L, eds). Boston: MIT.

Parr LA, Hecht E, Barks SK, Preuss TM, Votaw JR (2009) Face processing in the chimpanzee brain. Curr Biol 19:50-53. CrossRef Medline
Peeters R, Simone L, Nelissen K, Fabbri-Destro M, Vanduffel W, Rizzolatti G, Orban GA (2009) The representation of tool use in humans and monkeys: common and uniquely human features. J Neurosci 29: 11523-11539. CrossRef Medline

Petrides M (2005) Lateral prefrontal cortex: architectonic and functional organization. Philos Trans R Soc Lond B Biol Sci 360:781-795. CrossRef Medline

Raos V, Evangeliou MN, Savaki HE (2004) Observation of action: grasping with the mind's hand. Neuroimage 23:193-201. CrossRef Medline

Raos V, Evangeliou MN, Savaki HE (2007) Mental simulation of action in the service of action perception. J Neurosci 27:12675-12683. CrossRef Medline

Reivich M, Kuhl D, Wolf A, Greenberg J, Phelps M, Ido T, Casella V, Fowler J, Hoffman E, Alavi A, Som P, Sokoloff L (1979) The [18F]fluorodeoxyglucose method for the measurement of local cerebral glucose utilization in man. Circ Res 44:127-137. CrossRef Medline

Rilling JK, Barks SK, Parr LA, Preuss TM, Faber TL, Pagnoni G, Bremner JD, Votaw JR (2007) A comparison of resting-state brain activity in humans and chimpanzees. Proc Natl Acad Sci U S A 104:1714617151. CrossRef Medline

Rizzolatti G, Camarda R, Fogassi L, Gentilucci M, Luppino G, Matelli M (1988) Functional organization of inferior area 6 in the macaque monkey. II. Area F5 and the control of distal movements. Exp Brain Res 71:491-507. CrossRef Medline

Rizzolatti G, Fadiga L, Gallese V, Fogassi L (1996) Premotor cortex and the recognition of motor actions. Brain Res Cogn Brain Res 3:131-141. CrossRef Medline

Rozzi S, Ferrari PF, Bonini L, Rizzolatti G, Fogassi L (2008) Functional organization of inferior parietal lobule convexity in the macaque monkey: electrophysiological characterization of motor, sensory and mirror re- 
sponses and their correlation with cytoarchitectonic areas. Eur J Neurosci 28:1569-1588. CrossRef Medline

Schenker NM, Hopkins WD, Spocter MA, Garrison AR, Stimpson CD, Erwin JM, Hof PR, Sherwood CC (2010) Broca's area homologue in chimpanzees (Pan troglodytes): probabilistic mapping, asymmetry, and comparison to humans. Cereb Cortex 20:730-742. CrossRef Medline

Schiffer MB (1999) The material life of human beings: artifacts, behavior and communication. New York: Routledge.

Semaw S, Rogers MJ, Quade J, Renne PR, Butler RF, Dominguez-Rodrigo M, Stout D, Hart WS, Pickering T, Simpson SW (2003) 2.6-Million-yearold stone tools and associated bones from OGS-6 and OGS-7, Gona, Afar, Ethiopia. J Hum Evol 45:169-177. CrossRef Medline

Stout D (2011) Stone toolmaking and the evolution of human culture and cognition. Philos Trans R Soc Lond B Biol Sci 366:1050-1059. CrossRef Medline

Taglialatela JP, Russell JL, Schaeffer JA, Hopkins WD (2008) Communicative signaling activates 'Broca's' homolog in chimpanzees. Curr Biol 18: 343-348. CrossRef Medline

Taglialatela JP, Russell JL, Schaeffer JA, Hopkins WD (2011) Chimpanzee vocal signaling points to a multimodal origin of human language. PloS One 6:e18852. CrossRef Medline
Tennie C, Call J, Tomasello M (2009) Ratcheting up the ratchet: on the evolution of cumulative culture. Philos Trans R Soc Lond B Biol Sci 364:2405-2415. CrossRef Medline

Umiltà MA, Kohler E, Gallese V, Fogassi L, Fadiga L, Keysers C, RizzolattiG (2001) I know what you are doing. A neurophysiological study. Neuron 31:155-165. CrossRef Medline

Vanduffel W, Fize D, Peuskens H, Denys K, Sunaert S, Todd JT, Orban GA (2002) Extracting 3D from motion: differences in human and monkey intraparietal cortex. Science 298:413-415. CrossRef Medline

Visalberghi E, Fragazy D (2002) “Do monkeys ape?” Ten years after. In: Imitation in animals and artefacts (Dautenhahn CN, ed), pp 471-499. Cambridge, MA: MIT.

Von Bonin G (1948) The frontal lobe of primates; cytoarchitectural studies. Res Publ Assoc Res Nerv Ment Dis 27:67-83. Medline

Whiten A, Goodall J, McGrew WC, Nishida T, Reynolds V, Sugiyama Y, Tutin CE, Wrangham RW, Boesch C (1999) Cultures in chimpanzees. Nature 399:682-685. CrossRef Medline

Whiten A, McGuigan N, Marshall-Pescini S, Hopper LM (2009) Emulation, imitation, overimitation and the scope of culture for child and chimpanzee. Philos Trans R Soc Lond B Biol Sci 364:2417-2428. CrossRef Medline 